\title{
Políticas Afirmativas na \\ Pesquisa Educacional ${ }^{1}$
}

\section{Affirmative Action in Brazilian Educational Research}

\author{
Paulo Vinicius Baptista da Silva* \\ Carolina dos Anjos de Borba*
}

\begin{abstract}
RESUMO
Este artigo foi preparado a partir da pesquisa Educação e Relações Étnico-Raciais: o Estado da Arte, trazendo análise sobre a categoria "ações afirmativas". Na primeira parte são analisados dados das publicações identificadas, 94 artigos e 69 teses e dissertações. Os artigos tiveram aumento gradativo até 2012, com diminuição em 2013 e 2014; maior concentração nos estratos de avaliação qualis mais altos; publicados em revistas das regiões Sudeste e Centro-Oeste e distribuição de gênero de autoria equilibrada. As 54 dissertações e 15 teses tiveram aumento gradativo até 2011, com diminuição principalmente em 2013 e 2014; dispersão de programas e orientadores com concentração na Região Sudeste, seguida das Centro-Oeste e Sul. Na segunda parte apresenta-se uma síntese analítica dos 94 artigos e seus argumentos e resultados. Foram discutidos os temas recorrentes (argumentos sobre políticas afirmativas e estudos sobre experiências específicas os mais frequentes), temas emergentes e lacunas. $\mathrm{O}$ tema das políticas afirmativas na educação brasileira apresenta, nos artigos publicados em revistas da área de educação, um campo que foi crescente e com análises relevantes. Existem muitos temas a serem abordados pela pesquisa, em especial apontamos: as políticas afirmativas na pós-graduação e na docência; maior investimento em estudos sobre permanência, sobre mudanças nas universidades e polí-
\end{abstract}

1 Pesquisa financiada pelo Conselho Nacional de Desenvolvimento Científico e Tecnológico (CNPq), Coordenação de Aperfeiçoamento de Pessoal de Ensino Superior (CAPES), Fundação Araucária e Secretaria de Educação Continuada, Alfabetização, Diversidade e Inclusão do Ministério da Educação (SECADI/MEC).

* Universidade Federal do Paraná. Programa de Pós-Graduação em Educação. Núcleo de Estudos Afro-brasileiros. Curitiba, Paraná, Brasil. E-mail: pauloviniciusufpr@gmail.com. ORCID: https://orcid.org/0000-0001-9207-2439.E-mail: carolzinhadosanjos@gmail.com. ORCID: https:// orcid.org/0000-0003-3690-9411 
ticas curriculares que acompanham as políticas afirmativas; de políticas de identidade; estudos com abordagem mais geral ou sínteses.

Palavras-chave: Políticas afirmativas. Relações étnico-raciais. Estado da Arte.

\begin{abstract}
This paper analyses the affirmative action category from the Ethnic-Race Education in Brazil Report. In the first part are analyzed data of the identified publications, 95 articles and 69 theses and dissertations. The papers published had gradual increase until 2012, with decrease in 2013 and 2014; higher concentration in higher quality evaluation extracts; published in journals of the Southeast and Midwest regions; gender authorship distribution balanced. The 54 dissertations and 15 theses had a gradual increase until 2011, with a decrease mainly in 2013 and 2014; dispersion of programs and counselors with concentration in the Southeast, followed by the Midwest and South. The second part presents an analytical summary of the 95 articles and their arguments and results. The recurrent themes, emerging themes and gaps were discussed. The topic of affirmative policies in Brazilian education presents, in articles published in journals in the area of education, a field that has been growing and with relevant analyzes. There are many topics to be addressed by the research, in particular: affirmative policies in postgraduate and teaching; greater investment in studies on permanence, changes in universities and curricular policies that accompany affirmative policies; of identity policies; studies with a more general approach or syntheses.
\end{abstract}

Keywords: Affirmative action. Ethnic and race relations. Systematic review. Racism. Educational policies.

Este artigo foi preparado a partir da pesquisa Educação e Relações Étnico-Raciais: o Estado da Arte, trazendo análise sobre a categoria "ações afirmativas" na qual foram classificados os artigos, teses e dissertações localizados ${ }^{2}$. $\mathrm{Na}$ primeira parte, são analisados dados das publicações identificadas, 94 artigos e 69 teses e dissertações. Na segunda, apresentamos uma síntese analítica dos 94 artigos e seus argumentos e resultados.

2 Um grande agradecimento à bolsista de Iniciação Científica Daiane da Silva Vasconcelos, que preparou os gráficos que constam neste artigo e teve participação destacada tanto para a análise dessa categoria, quanto no apoio à coordenação da pesquisa. 


\section{Uma visão panorâmica dos artigos, dissertações e teses identificados}

A categoria de políticas afirmativas apresentou o maior número de artigos de nosso universo, 95 artigos. As publicações sobre o tema têm uma relação direta com o contexto de luta por igualdade racial na sociedade brasileira. Desde os anos 1950, a demanda por vagas preferenciais nas universidades faz parte das reivindicações dos movimentos negros, nos anos 1980 essas demandas chegaram ao Congresso Nacional e foram apresentadas como propostas de igualdade racial em grandes mobilizações, por exemplo, a Assembleia Nacional Constituinte de 1986 e o debate anterior à LDB - Lei de Diretrizes e Bases de 1996. Nos anos 1990, o governo brasileiro assumiu uma indicação interna de implementar políticas afirmativas para a população negra no Ensino Superior, via um Grupo de Trabalho Interministerial que funcionou de 1994 a 1997, tendo sido implantado como resposta à Marcha Zumbi dos Palmares pela vida e contra todas as formas de discriminação (realizada em 20 de novembro de 1995). Nessas décadas, onde essas proposições se avolumavam, demandando políticas de promoção de igualdade específicas para a população negra, é possível observar o silêncio no debate acadêmico, sendo raras as publicações acadêmicas sobre esse tema em todo o período. Nos anos 2000, a universidade brasileira introduziu a adoção de políticas afirmativas no modelo de cotas para ingresso de candidatos/as negros/as nas universidades, processo iniciado em 2002 no Rio de Janeiro (UERJ e UENF) e expandido em 2003 (UNEB, UEMS e UNB) e 2004 (UEL, UPFR, UFBA, UFAL), desde então tendo grande ampliação até a aprovação da Lei 12.711 em 2012 que define políticas de cotas para todas as universidades federais. Esta adoção das "cotas raciais" nas universidades foi acompanhada de um amplo debate público e em nossa interpretação este debate tem relação direta com a entrada de um tema que não existia nas publicações acadêmicas dos anos 1990 e se torna em nossa amostra o tema com maior número de publicação de artigos nos anos 2003-2014 no campo da Educação das Relações. Necessário observar que, por um lado, esta pesquisa buscou ser exaustiva nas buscas em revistas e programas de pós-graduação, da área de educação, por outro, nossa amostra é limitada a artigos, teses e dissertações dessa área, revistas e programas de pós-graduação de outras áreas como a Sociologia, Ciência Política, Antropologia e Direito também publicaram uma quantidade significativa de trabalhos sobre o tema. Tomados tais dados, este estudo confirma a afirmação de Santos (2012) de que as publicações revelam a constituição de uma significativa produção acadêmica sobre políticas afirmativas nas universidades brasileiras. Nossa hipótese explicativa para um tema 
que era silenciado passar a ser o mais proeminente em artigos é que os debates público e midiático que se retroalimentam foram determinantes para o amplo interesse sobre a temática e sobre a progressiva ampliação das publicações de artigos, dissertações e teses. Nota-se que as publicações de artigos aumentaram progressivamente até um salto em 2012 (24 artigos), apresentando uma queda nos dois anos posteriores (Gráfico 1).

GRÁFICO 1 - ANO DE PUBLICAÇÃO DOS ARTIGOS

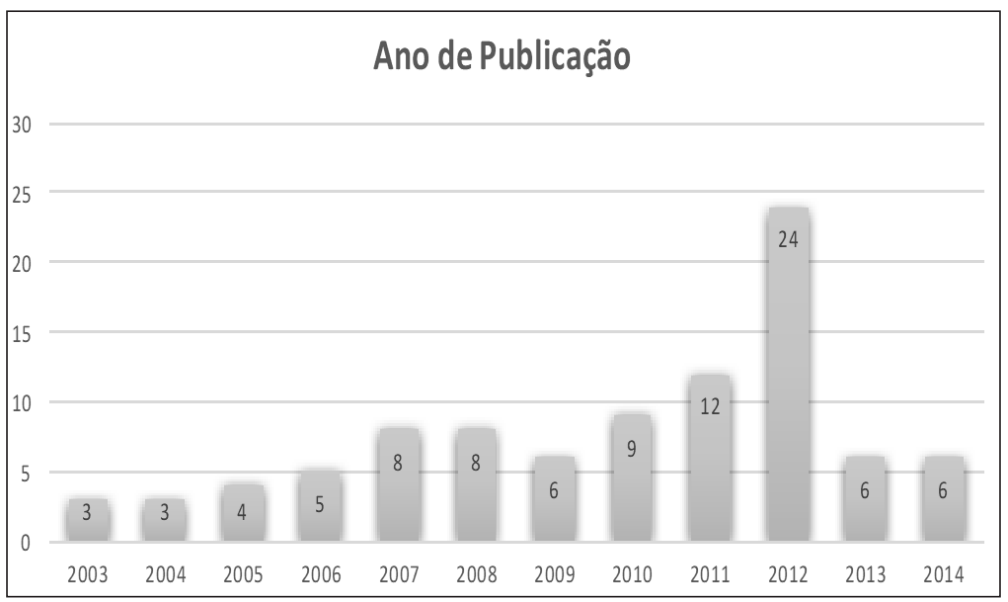

FONTE: Pesquisa Educação e Relações Étnico-Raciais: O Estado da Arte, 2017.

O ano de votação pelo Supremo Tribunal Federal sobre a constitucionalidade das cotas e da aprovação de cotas nas Universidades Federais coincide com o ápice das publicações, em parte com este número tão expressivo em função de publicações de dossiês com conjuntos de artigos sobre o tema. Possivelmente os/as editores/as tiveram maior sensibilidade com uma presença expressiva no debate público naquele momento.

Conforme dados dispostos no Gráfico $2^{3}$, a distribuição da classificação das revistas apresenta que o tema entrou nas áreas de maior reconhecimento acadêmico, visto que a categoria com maior incidência de artigos foi a B1 (27); na categoria A1 o número de 16 artigos publicados é expressivo e superior aos 6 artigos publicados no extremo oposto, o estrato B5; a soma dos artigos publicados nos três estratos mais altos é 49 , superior ao de artigos publicados nos três estratos mais baixos, que foi 37 .

3 Esta classificação foi realizada no período de levantamento dos dados, em 2015, quando o qualis 2013 estava disponível na plataforma. 
GRÀFICO 2 - CLASSIFICAÇÃO QUALIS DAS REVISTAS

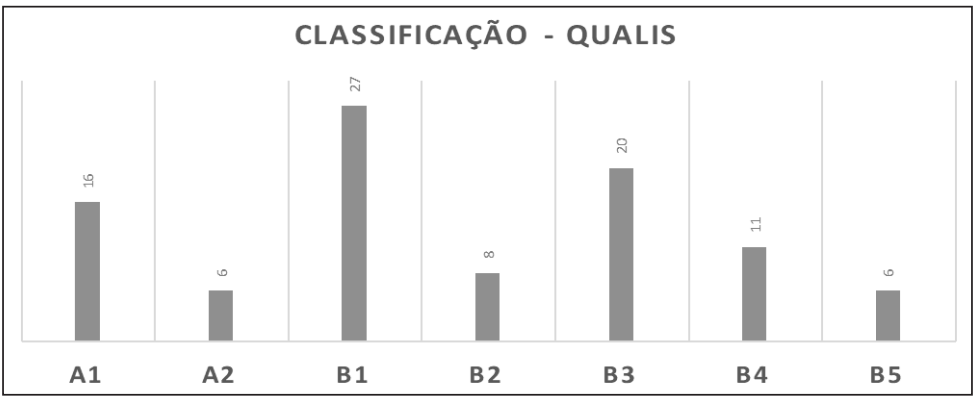

FONTE: Pesquisa Educação e Relações Étnico-Raciais: O Estado da Arte, 2017.

A distribuição das regiões das revistas onde os artigos foram publicados (Gráfico 3) contou com prevalência do Sudeste (38\%) e Centro-Oeste (34\%) um índice considerável do Sul (19\%) e uma ausência no Nordeste (2\%) e Norte ( $0 \%)$.

GRÁFICO 3 - REGIÃO DE PUBLICAÇÃO DAS REVISTAS

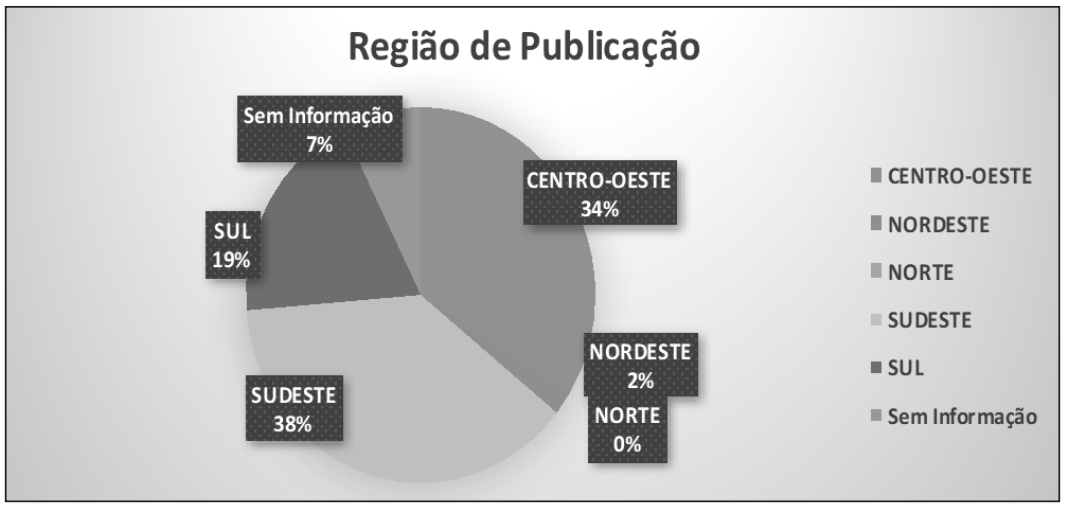

FONTE: Pesquisa Educação e Relações Étnico-Raciais: O Estado da Arte, 2017.

Essa distribuição se relaciona com a distribuição das revistas, com concentração no Sudeste e Sul. Os artigos tiveram uma baixa presença em revistas do Nordeste, o que surpreende em função de existir presença importante de revistas de educação na região e das universidades do Nordeste figurarem entre as primeiras que adotaram políticas afirmativas para a população negra (UNEB - Universidade do Estado da Bahia, UFBA - Universidade Federal da Bahia e UFAL - Universidade Federal de Alagoas). A alta presença em revistas no 
Centro-Oeste foi em boa medida em função da revista da ABPN (Associação Brasileira de Pesquisadores/as Negros/as), com sede em Brasília.

Em relação à distribuição de gênero de autoras/es esta categoria apresentou uma distribuição equitativa, com $38 \%$ de autoria exclusivamente masculina, $35 \%$ exclusivamente feminina e $27 \%$ com coautores identificadas/os pelo nome como de ambos os gêneros (Gráfico 4).

\section{GRÁFICO 4 - GÊNERO DE AUTORES/AS DE ARTIGOS}

\section{Gênero de autores/as}

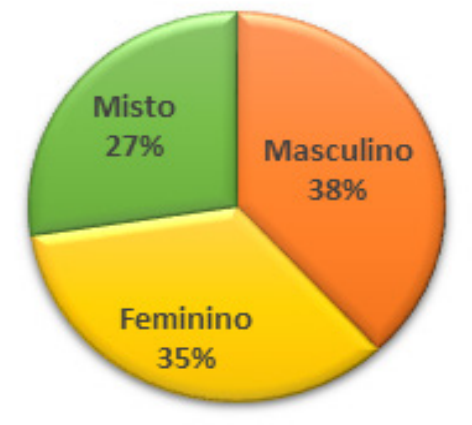

Masculino $\square$ Feminino $\mathbf{M}$ isto

FONTE: Pesquisa Educação e Relações Étnico-Raciais: O Estado da Arte, 2017.

Foram contabilizadas 69 pesquisas, fruto de conclusão de pós-graduação identificadas para análise, sendo 54 dissertações e 15 teses. $\mathrm{O}$ ano de publicação/ defesa de teses e dissertações seguiu um padrão similar ao dos artigos, com aumento gradativo a partir de 2004, ápice em 2011 (para artigos foi 2012), diminuição nos últimos anos, mas manutenção de um certo equilíbrio entre 2008 e 2014 (variações entre 6 e 14\%, exceto 2011), contando 2010 com percentual mais baixo $(6 \%)$ e 2011 mais alto (20\%). Novamente a hipótese explicativa pelo interesse ao tema passa pelo debate público e midiático, sendo que após a definição do STF - Superior Tribunal Federal pela constitucionalidade das cotas raciais e aprovação da Lei 12.711 em 2012 que definiu sistema de cotas para todas as universidades federais, o debate público perdeu em intensidade e o interesse na pesquisa sobre o tema apresenta indicativo de acompanhar tal tendência. Ao mesmo tempo em que é possível identificar as políticas afirmativas como tema presente na pesquisa em educação, é factível afirmar que é um tema com 
participação relativamente pequena na área, em especial o número de 15 teses defendidas em 12 anos é tímido, se considerados o grande número de teses em educação defendidas neste período e o fato de ser maior área na pós-graduação brasileira, com programas muito grandes em termos de número de docentes, discentes, defesas, etc.; que experimentou um crescimento muito significativo nas gestões do Presidente Lula (2003-2010) e Dilma (2011-2016). Ou seja, é um tema que gerou interesse e apresenta um rol de trabalhos concluídos, ao mesmo tempo em que permanece como temática minoritária na área (Gráfico 5).

\section{GRÁFICO 5 - ANO DE PUBLICAÇÃO DAS TESES E DISSERTAÇÕES}

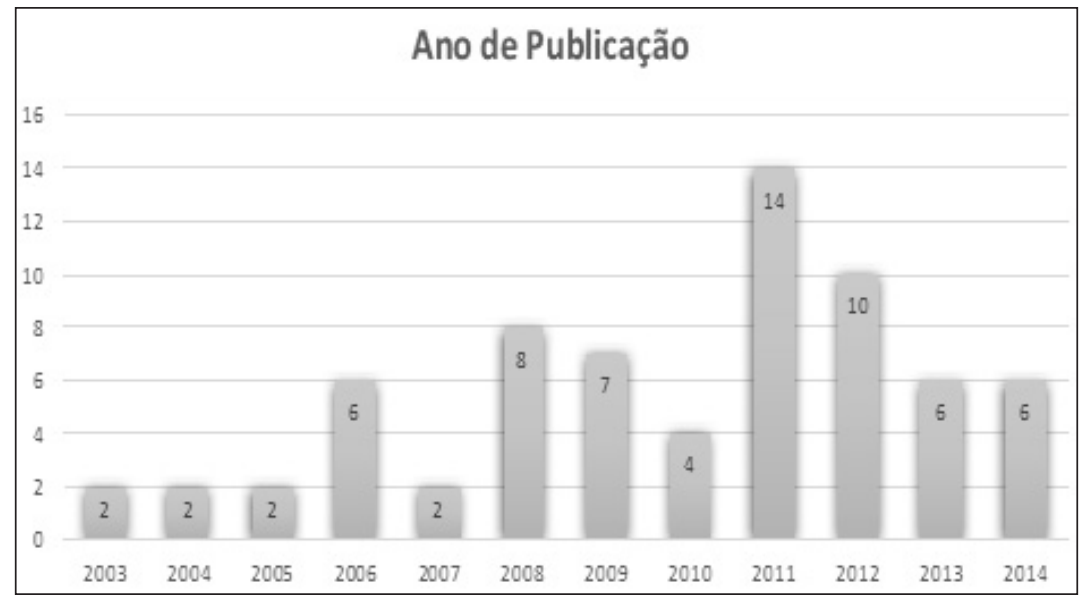

FONTE: Pesquisa Educação e Relações Étnico-Raciais: O Estado da Arte, 2017.

Os orientadores das teses e dissertações tiveram bastante dispersão, observando-se um total de 55 orientadoras/es para os 69 trabalhos. O maior número de trabalhos de conclusão aprovados foi de Mariluce Bittar (UCDB - Universidade Católica Dom Bosco, em Campo Grande. MS) que orientou 4 dissertações. Portanto, ainda falta na área de educação uma produção de médio/ longo prazo com foco na temática e sua inserção mais forte em grupos de pesquisa. Em relação ao gênero de orientadores, a distribuição foi relativamente equilibrada, com proporção um pouco maior feminina $(55 \%)$ em relação à masculina (45\%). A distribuição por gênero de autoras/es foi mais equilibrada ainda, com $49 \%$ de autoria feminina e $51 \%$ masculina.

Em relação às instituições onde os trabalhos foram defendidos observa-se relativa dispersão com uma importante participação da UNB - Universidade de Brasília, com 7 trabalhos, seguida da USP - Universidade de São Paulo e 
UCDB com 5. A UNEB figura entre outras instituições do Sudeste e Sul com diversos trabalhos concluídos sobre o tema (Gráfico 6).

GRÁFICO 6 - PRINCIPAIS INSTITUIÇÕES DE DEFESA DE TESES E DISSER-
TAÇÕES

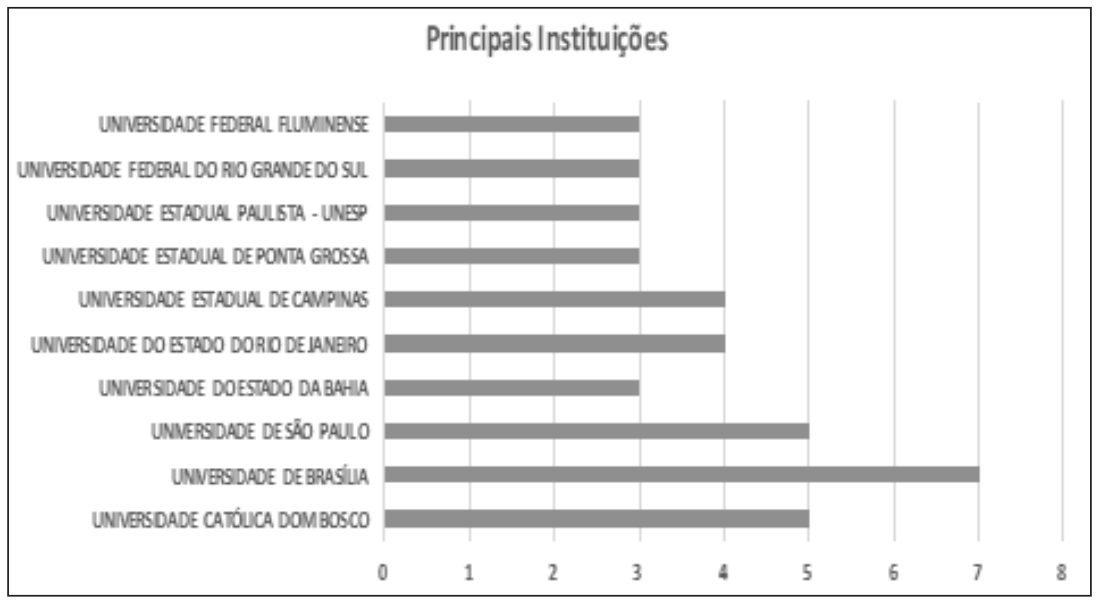

FONTE: Pesquisa Educação e Relações Étnico-Raciais: O Estado da Arte, 2017.

A distribuição de defesas de teses e dissertações em programas da área de educação, por região, revela uma proporção maior no Sudeste (33,48\%), que pode se relacionar com a concentração de programas de pós-graduação nesta região. Seguiram as regiões Centro-Oeste (22\%) e Sul (19\%). Em relação à baixa incidência de artigos em revistas com sede na Região Nordeste, ocorreu uma proporção mais significativa de trabalhos de conclusão, ou seja, a região que abriga a maior proporção de população negra foi o espaço de algum acolhimento da temática das cotas raciais na pós-graduação em educação. A região Norte, por sua vez, teve participação bastante tímida, com um único trabalho (Gráfico 7).

$\mathrm{O}$ índice de financiamento foi bastante baixo, com somente 17 dos 69 trabalhos, sendo sete trabalhos com informação de serem financiados pela CAPES - Coordenação de Aperfeiçoamento de Pessoal de Nível Superior, três pela Fundação Ford, um pelo CNPq - Conselho Nacional de Desenvolvimento Científico e Tecnológico, três pela FABESB Fundação de Amparo à Pesquisa do Estado da Bahia e três por outras fundações estaduais. 


\section{Distribuição Regional}

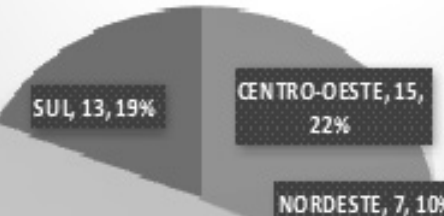

ICENTRO-OESTE

NORDESTE, $7,10 \%$

UNORDESTE

WNORTE

SUDESTE, $33,48 \%$

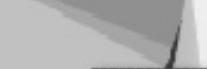

NORTE, $1,1 \%$

SUDESTE

nsul

FONTE: Pesquisa Educação e Relações Étnico-Raciais: O Estado da Arte, 2017.

\section{O conteúdo dos artigos}

Em função da limitação de espaço, a análise sobre os resultados neste artigo foca somente nos artigos. Iniciamos a análise discutindo os temas recorrentes no conteúdo dos artigos.

A polarização em torno de argumentos contrários ou favoráveis às cotas para negros nas universidades atingiu também o debate acadêmico. Podemos afirmar que tanto o debate acadêmico quanto o debate midiático apresentaram mútua influência, pois os argumentos circularam em ambos meios discursivos e, muitas vezes, mobilizaram dados educacionais ou étnico-raciais do Brasil. Especialmente artigos publicados no início (mas não só) do período de análise (2003) apresentavam posição de forma bastante veemente. Alguns artigos não tinham nenhuma base empírica nova, pois eram organizados em torno de argumentos contra ou pró-cotas raciais.

Nos artigos que apresentaram posição contrária às políticas afirmativas, os argumentos recorrentes foram que as cotas não contribuiriam para alterar a estrutura social (AZEVEDO, 2004; HERMIDA, 2004; LIMA, 2010a; 2010b; 2011). Esses artigos apresentam uma análise numa perspectiva neomarxista que considera que o foco de luta deveria ser a "centralidade capital trabalho" 
(LIMA, 2011), o processo de reestruturação produtiva (LIMA, 2010a, 2010b), as contradições do sistema capitalista (HERMIDA, 2004), e fazem uma crítica ao fato das cotas não alterarem o quadro de distribuição de capital, operando para maquiar contradições do capitalismo (HERMIDA, 2004; LIMA, 2010b; 2011) e não atingiriam os problemas existentes no sistema educacional brasileiro (HERMIDA, 2004). As contradições na sociedade capitalista, competitiva e individualista seriam somente maquiadas e luta mais importante, por uma sociedade universalista e socialista, seria contraposta pelas lutas por identidades raciais, que atuariam dentro da lógica da sociedade capitalista (AZEVEDO, 2004, p. 216). Vinculada a esse conjunto de argumentos está a discussão sobre a educação básica, cuja melhora poderia significar a igualdade de condições para ingresso na Universidade. Sobre esse item fica explícita uma contradição no texto de Azevedo (2004) que por um lado faz críticas contundentes à sociedade capitalista, competitiva e individualista e por outro defende que o exame vestibular não é racializado e que as cotas raciais retiram o "direito de concorrer a 100\% das vagas movido pelo seu próprio esforço, disciplina e talento, já que o quesito identidade de cor teria precedência sobre o mérito individual de cada vestibulando" (2004, p. 214). Um outro conjunto de argumentos afirma que as políticas afirmativas para negros operariam para racializar o Brasil (AZEVEDO, 2004; SILVA, MOZART, 2010), desconsiderando ser o Brasil um "local da mestiçagem" (SILVA, MOZART, 2010); promovendo uma "racialização pelo alto" na qual o Estado "racializado" teria dificuldade em promover a igualdade para todos/as (AZEVEDO, 2004, p. 215; MAGGIE, 2006). O artigo de Maggie não é um ensaio, pois apresenta uma série de dados coletados em etnografias e survey realizado em 21 escolas do Rio de Janeiro. O argumento defendido pela autora com base na análise destes dados foi que os estudantes não têm no preconceito e discriminação racial temas centrais em suas vidas (embora sejam muito relevantes para estudantes autoclassificados/as pretos/as), por isso uma política afirmativa definida pelo Estado seria uma "engenharia social" que "obrigaria" estudantes a se pensarem como negros/as ou brancos/as, operando para a racialização da sociedade. O esforço principal do ensaio de Azevedo (2004) é similar, pois afirma que as cotas raciais teriam o condão de racializar o Brasil e que o uso de critério racial como política de Estado operaria para arraigar a "raça" como instrumento de Estado. O Brasil seria um local de encontro salutar entre as raças (SILVA, MOZART, 2010), orientado pela crença no mito da democracia racial (AZEVEDO, 2004) no qual seria difícil ou impossível classificar quem é negro, outro empecilho para as políticas afirmativas para negros/as (AZEVEDO, 2014).

Alguns artigos buscaram apresentar uma discussão sobre os argumentos pró e contra as cotas raciais (GUIMARÃES, 2003; MOEHLECKE, 2004; DO- 
MINGUES, 2005; OLIVEN, 2007; HASS, LINHARES, 2012). Ao passo que Azevedo (2004) afirmou que as cotas raciais nos Estados Unidos da América - EUA foram um fracasso como política de promoção de igualdade, os artigos de Neves (2003); Moehlecke (2004); Oliven (2007); Xavier e Xavier (2009) realizaram comparações entre particularidades dos processos nos EUA, com seus resultados positivos e suas limitações, para analisar o contexto brasileiro.

Esses estudos e diversos outros favoráveis às políticas afirmativas apresentam como argumentos mais frequentes:

- os dados e indicadores de desigualdade racial na educação brasileira e no Brasil contemporâneo (GUIMARÃES, 2003; MOEHLECKE, 2004; DOMINGUES, 2005; NEVES, 2005; PIOVESAN, 2005; TRAGTENBERG et alii, 2006; VALENTE, 2006; VELLOSO, 2010; AGOSTINHO e BREGA FILHO, 2011; NEVES, LIMA e SANTOS, 2012; MARCON, 2012; SANTOS, SOUZA e SASAKI, 2012; VIEIRA, 2012; SILVA FILHO, 2014);

- o Brasil tem uma estrutura racializada (portanto não são políticas afirmativas que iriam gerar racialização) e as políticas afirmativas operam para constituir igualdade dentro desta estrutura desigual (GUIMARÃES, 2003; NEVES, 2003; 2005; MOEHLECKE, 2004; DOMINGUES, 2005; PIOVESAN, 2005; TRAGTENBERG et alii, 2006; VALENTE, 2006; RANGEL, 2008; MARQUES, 2010; MARCON, 2012; SANTOS, SOUZA e SASAKI, 2012);

- a necessidade de políticas afirmativas como forma compensatória pelas discriminações que pesaram contra a população negra ao longo dos séculos (BRASILEIRO, 2003; NEVES, 2003; 2005; DOMINGUES, 2005; SANTOS, FERREIRA, 2012; MARCON, 2012);

- o papel dos movimentos negros nas proposições e lutas políticas por políticas afirmativas (GUIMARÃES, 2003; DOMINGUES, 2005; MARQUES, 2010; QUEIRÓZ, 2012; MARCON 2012; SANTOS, SOUZA, SASAKI, 2012);

- a necessidade de ampliar políticas de igualdade na universidade brasileira (GUIMARÃES, 2003; NEVES, 2003; PIOVESAN, 2005; VALENTE, 2006; RABELLO, 2008; VELLOSO, 2010; TAFURI, 2011; AGRA, 2012; VIEIRA, 2012; SILVA FILHO, 2014) e dados de programas de cotas já adotados sustentam tal papel observado (VELLOSO, 2010; VIEIRA, 2012);

- a distribuição de poder nas profissões de maior prestígio social, e no campo científico são essencialmente brancas e as cotas podem operar para trazer mudanças neste processo, possibilitando a participação de pesquisadores/as negros/as, sujeitos historicamente excluídos destes 
processo (CARVALHO, 2007; TAFURI, 2011; AGRA, 2012; MARCON, 2012);

- o "mérito" acadêmico é construção política e social e as políticas afirmativas confrontam a meritocracia (MARQUES, 2010; QUEIRÓZ, 2012);

- a "brancura" significa acesso a vantagem social e as políticas afirmativas seriam resposta para diminuir tais vantagens (AGRA, 2012);

- a necessidade de inclusão de negros/as nos processo de formação em tecnologia (SILVA, I., 2007).

Dois estudos fizeram uma discussão específica dos argumentos contrários às políticas afirmativas, ao conjunto de "falsas objeções às cotas para negros na universidade", discutindo: a identidade de raça/cor no Brasil; os efeitos de cotas na educação básica; o "mérito" acadêmico; o racismo no Brasil e a constitucionalidade das cotas (RANGEL, 2008; QUEIRÓZ, 2012).

Alguns artigos apresentaram argumentos ou tiveram como foco a questão da constitucionalidade das cotas, no período anterior ao julgamento pelo STF, cotejando normativas internacionais com as nacionais e concluindo que o ordenamento brasileiro é compatível com as políticas afirmativas para negros/ as (PIOVESAN, 2005; SILVA, I., 2007; SILVA, L., 2007; 2010; SILVA e NEGRÃO, 2012), o que veio a se manifestar no julgamento do STF em 2012. Os artigos examinaram não somente a constituição, mas também marcos jurídicos internacionais e brasileiros na ótica dos Direitos Humanos (PIOVESAN, 2005; SILVA, I., 2007; SILVA, L., 2007; 2010; SILVA e NEGRÃO, 2012).

Vinculados à discussão sobre desigualdades sociais alguns artigos trouxeram tratamento de dados quantitativos sobre desigualdade de raça/cor (ANDRADE, DACHS, 2007; BELTRÃO e TEIXEIRA, 2008; OSÓRIO 2009). Com foco menor nos argumentos pró ou contra as cotas, apresentando uma série de tabulações e análises valendo-se de dados primários, os pesquisadores do IBGE - Instituto Brasileiro de Geografia e Estatística - Beltrão e Teixeira (2008) fornecem muitos subsídios sobre a desigual distribuição étnico-racial nas carreiras superiores e na interseccionalidade com gênero. Os estudos desse grupo, discutindo as desigualdades de raça e classe social, apontam como o déficit no ensino superior é de renda e de raça cor (ANDRADE, DACHS, 2007; BELTRÃO e TEIXEIRA, 2008; OSORIO, 2009).

Um outro grupo de estudos relacionado com o debate público sobre cotas raciais são as análises sobre a cobertura midiática. Duas pesquisas analisaram cobertura do jornal $O$ Globo e ambas detectaram cobertura parcial, ambígua, que chama a atenção para possíveis resultados negativos de cotas raciais (FISCHMAN e SALES, 2008; VIENBRANTZ, CASONATTO, SOMERS, 2012). Na análise sobre as reportagens e editorias publicadas sobre o tema 
entre 2010 e 2010, O Globo apesenta mais editorias e opiniões de jornalistas, com tom contrários às cotas e, ao longo dos anos, passa a "defender" políticas afirmativas focadas no ensino básico público. O jornal A Folha de São Paulo publicou muitos editoriais contrários às políticas afirmativas, mas apresentou mais reportagens sobre o tema no qual se expressaram múltiplos pontos de vistas (VIENBRANTZ, CASONATTO, SOMERS, 2012). Um estudo focou em debate no Orkut após aprovação das cotas raciais na UFGRS - Universidade Federal do Rio Grande do Sul, analisando quatro comunidades, sendo as de maior número de postagens e membros a "Contra as cotas na UFRGS" na qual os discursos se organizam por perguntas retóricas que levam a respostas que reforçam argumentos propostos pelos proprietários da comunidade, por repetições de palavras de ordem em resposta em uníssono, pela escolha de vilões (Governo Lula, Reitor da UFRGS, DCE - Diretório Central do Estudantes). Na segunda maior comunidade, "Cotas na UFRGS - Vitória", o articulador argumentativo é a questão da diversidade, e o discurso foi descrito como "espaço de debate bastante qualificado, com a presença de pontos de vista e de posições distintas sobre a questão das cotas. É comum um tema de debate desencadear várias postagens com relativo nível de aprofundamento" (WIELEWICK, OLIVEIRA, 2008, p. 98). Outro artigo analisou comentários postados na web acerca de artigo on line publicado em revista de circulação nacional sobre o tema políticas afirmativas e identificou os argumentos contrários principalmente sobre qualidade da educação pública, ao passo que os favoráveis mobilizaram principalmente argumentos sobre a desigualdade racial no Brasil e necessidade de reparação histórica (CASTRO, KOELZER, CARMARGO, BOUSFIELD, 2014).

Em relação a esse debate sobre as cotas, temos ainda artigos que buscaram identificar em universitários sua percepção e/ou atitude diante de cotas raciais (BRANDÃO, MARINS, 2007; NAIFF, NAIFF E LOUBACK, 2013; LIMA, NEVES, SILVA, 2014). Ao passo que Brandão e Marins (2007) identificaram estudantes preponderantemente contra as cotas, tanto estudantes brancos/as como negros/as; Naiff, Naiff e Louback (2013) verificaram um apoio muito forte de cotista raciais para as políticas de cotas.

O primeiro objeto dos artigos foi o debate e argumentos pró e contra cotas raciais no Ensino Superior. Um segundo objeto muito frequente dos estudos foram os programas específicos de políticas afirmativas. à medida em que diversas universidades adotavam políticas afirmativas, diversas pesquisas buscaram controlar resultados de tais políticas e passaram a ser publicadas. A maior parte dos artigos se volta para a descrição e análise de casos específicos, encontrando-se estudos sobre processo de discussão em conselhos e adoção de políticas afirmativas; dados de entrada e de perfil de candidatos/as em concursos 
vestibulares; desempenho e comparação rendimento e/ou evasão de cotistas e não cotistas.

Um estudo sobre dados do vestibular da UFSC - Universidade Federal de Santa Catarina - em 2004 (TRAGTENBERG et al, 2006) precedeu a implementação de políticas afirmativas naquela universidade, realizou uma série de simulações sobre número de vagas e cotas para egressos de escola pública e negros/as, concluindo que somente esta última teria impacto na promoção de entrada de discentes negros/as naquele processo seletivo.

Alguns estudos colocaram o foco nos processos de implantação das políticas afirmativas em diferentes universidades e diferentes modelos: Queiróz e Santos, 2006 sobre a UFBA; Silva, P., 2008 sobre a UFSCAR - Universidade Federal de São Carlos; Hass e Linhares, 2012 sobre UERJ - Universidade Estadual do Rio de Janeiro, UENF - Universidade Estadual do Norte Fluminense e UNB; Ferreira e Tenório, 2012 sobre a UFBA; Rosa, 2014 sobre aspectos gerais no Brasil. A comparação dos processos na UERJ e UENF via decreto do Governo e UNB via discussão interna coletiva (com a participação da comunidade universitária, do NEAB-UNB e dos movimentos negros) tem tal modelo apontado como mais adequado, via autonomia universitária (HASS, LINHARES, 2012). Sobre o processo da UFSCAR foram discutidos os desafios derivados da implantação das cotas raciais, argumentando que "um dos critérios para avaliação da excelência da produção acadêmica é sua vinculação com necessidades e anseios dos segmentos que compõem a sociedade, bem como suas repercussões na vida social" (SILVA, P., 2008, p. 42).

O impacto das políticas afirmativas no acesso foi outro ponto que foi objeto de um grupo de pesquisas. O início das cotas raciais na UFBA e seus dados positivos no ingresso de estudantes negros/as foram discutidos por Queiróz e Santos (2006). No primeiro ano de cotas raciais na UEPG - Universidade Estadual de Ponta Grossa, 2007, observou-se a entrada de estudantes negros/ as, mas abaixo dos $15 \%$ reservados, sendo que em 12 cursos não houveram candidatos/as para as cotas para negros/as (CERRI, PLÁ, 2008). Na UFRGS, observou-se uma baixa ocupação das vagas reservadas para negros/as, creditado ao ponto de corte do concurso vestibular (DOEBBER, GRISA, 2012). $\mathrm{Na}$ UFABC - Universidade Federal do ABC, em três vestibulares, a tendência foi de decréscimo de candidatos da região do $\mathrm{ABC}$, de egressos de escolas públicas, de negros e indígenas, diminuindo o impacto das cotas no acesso (SILVA, MOSCA, ZIMERMAM, 2012). Na UFMA - Universidade Federal do Maranhão (MACIEL, 2012) e na UNB (VELLOSO E CARDOSO, 2011), as políticas tiveram melhores resultados e, para a UNB os autores a conclusão é que as cotas raciais são responsáveis pelo ingresso de estudantes negros/as 
na UNB e que a simulação duplicação de vagas teria um efeito diminuto em relação às cotas raciais adotadas na UNB.

Em relação à comparação de rendimento entre cotistas e não cotistas, Queiróz e Santos apresentaram os dados de 2006 na UFBA que revelaram um coeficiente de rendimento superior ao dos não cotistas na maior parte dos cursos (QUEIRÓZ, SANTOS, 2006). Em artigo posterior foram analisados os rendimentos dos ingressantes pelas cotas na UFBA em dois momentos, no segundo e no nono semestre dos cursos, e os cotistas revelaram um significativo aumento de seu coeficiente de rendimento no final dos cursos, em relação ao início (SANTOS, 2012). No que se refere à reprovação por faltas, o desempenho dos cotistas foi superior ao dos não cotistas.

Em outro conjunto de pesquisas, foram analisados os resultados de ingressos via programas de bônus, com estudos sobre dados da Unicamp - Universidade Estadual de Campinas (BONILHA, 2011); da UFMG - Universidade Federal de Minas Gerais (PEIXOTO, BRAGA, 2012; ARANHA, PENA, RIBEIRO, 2012) e gerais (SOUZA, 2012). As pesquisas apontaram para resultados positivos nas diversas universidades, alterando o perfil dos/as aprovados/ as no vestibular. Embora todos os artigos publicados sobre a modalidade de bônus apresentam resultados favoráveis, a tendência foi das universidades que adotavam este modelo passarem a adotar posteriormente o modelo de cotas (a UFMG e universidades federais pela aprovação da Lei 12.711 em 2012, a Unicamp e a USP em processos autônomos). Possivelmente a entrada de estudantes negros/as em maior proporção impulsionou movimentações internas de ativistas. E a compreensão de movimentos sociais é que as cotas apresentam melhores resultados em termos de ingresso, além do aspecto relevante que é constituir-se também como política de identidade.

Acerca da permanência também foram publicados alguns resultados de pesquisas. Entrevistas com estudantes que usufruíram de programas de permanência revelaram um importante papel destes programas em suas trajetórias (SOUZA, BITTAR, 2013). O Programa Conexões de Saberes como política afirmativa revelou impacto positivo na inclusão de estudantes de perfil socioeconômico baixo e atuação relevante como políticas afirmativas (FERRAZ, 2009; SOUZA, PERES, 2012); o desenvolvimento de extensão e pesquisa de forma integrada ao ensino, intercâmbio com as comunidades de origem que atuaram positivamente para a permanência dos/as discentes (FERRAZ, 2009). O monitoramento de um programa de permanência de estudantes negros numa instituição privada de Porto Alegre identificou a discriminação racial como agente principal na desistência destes estudantes (JULIO, STREY, 2009). Uma análise das políticas de permanência em universidades federais apontou pouco suporte no espaço universitário; nenhuma mudança observada nos projetos po- 
líticos pedagógicos e o aumento nas bolsas de assistência entre 2007-2010 sem levar em consideração as cotas no vestibular (SILVA, MOSCA, ZIMERMAM, 2012). Dados do Censo do Ensino Superior de 2012 revelaram tempo médio em atividades extracurriculares maior entre os cotistas do que os não cotistas, com maior engajamento de cotista em maior número de atividades relacionadas a faculdades, concluindo que os dados permitem afirmar que os cotistas tendem a integrar-se mais amplamente às atividades acadêmicas do que os demais estudantes (TTRAVITZKI, RAIMUNDO, 2012).

Outro foco de algumas pesquisas foi a identidade de discentes negros e cotistas. Dois estudos apontaram os programas de políticas afirmativas como atuantes para a construção de identidade racial positiva dos/as estudantes (BAKES, 2010; HOLANDA, WELLER, 2014). Um dos artigos sobre esta temática propõe a construção da cidadania pela "reescrita das diferenças" (conceito de Peter Mclaren) via a ruptura do silêncio sobre as relações raciais nos currículos escolares e universitários (AGRA, 2012). Em outro estudo que entrevistou jovens negras que ingressaram pelo sistema de cotas na UNB, as mesmas revelaram trajetória com vivência na infância de situações constrangedoras de racismo e na Universidade, por um lado construção positiva de identidade racial e aceitação em seus cursos, por outro a vivência de preconceitos de raça, gênero ou sexualidade na universidade (HOLANDA, WELLER, 2014). Em artigo que apresenta indicadores sobre mobilidade ascendente de mulheres negras a partir das políticas de cotas raciais, propõe que o impacto em egressas do ensino superior é relevante e sugere a realização de estudos sobre egressos, diante da ausência de pesquisa com este foco (CORDEIRO, 2013).

O PROUNI (Programa Universidade para Todos) foi analisado por alguns estudos sobre seus resultados, sendo dois artigos sobre a PUC/MG (ARAUJO, CORREAA, 2011; OLIVEIRA, CONTARINE, CURY, 2012), um sobre a PUC/ RJ (SANTOS, 2012) e um sobre o Unileste/MG (OLIVEIRA, MOLINA, 2012). O primeiro artigo sobre a $P U C / M G$ apresenta interpretação diferente dos demais, apresentado alguns dados de entrada na referida universidade para exemplificar o crescimento do programa, e realizando uma crítica sobre o PROUNI como forma de combate efetivo das desigualdades sociais (com discussão teórica, dados no artigo são escassos). O outro estudo tem interpretação distinta sobre o PROUNI como política de diversidade no Ensino Superior, analisa desempenho de bolsistas do PROUNI na PUC Minas, sendo que a maioria dos bolsistas apresentou desempenho, entre 2005 e 2008, bons e muitos bons, e 252 bolsistas foram "destaque acadêmico" (OLIVEIRA, CONTARINE, CURY, 2012). Aproxima-se em diversos aspectos a análise de dados de discentes da PUC/RJ que ingressaram via PROUNI (SANTOS, 2012), que aponta além dos resultados satisfatórios, o fato dos beneficiários do PROUNI que ingressaram 
entre 2005 e 2010 pertencerem a grupos de cor, classe social, renda e origem escolar pouco representados no ensino superior; a percepção das desigualdades de origem como ponto de interação e diálogo entre bolsistas e não bolsistas; a contribuição para bons resultados de estrutura de apoio a estudantes pobres que já existia previamente na PUC/RJ. O outro estudo discute as mudanças ocorridas em currículos e o atendimento à demanda de especificidades de estudantes negros/as, apontando as limitações e as mudanças observadas na Unileste/ MG (OLIVEIRA, MOLINA, 2012). Os estudos apontam para a efetividade do PROUNI como política de diversidade de classe social, origem e raça/cor na Universidade (OLIVEIRA, CONTARINE, CURY, 2012; OLIVEIRA, MOLINA, 2012; SANTOS, 2012).

Alguns artigos trataram de temas específicos. A Faculdade Zumbi dos Palmares em São Paulo é uma experiência única no Brasil de "faculdade negra", com $55 \%$ dos/as docentes e $80 \%$ dos discentes autodeclarados/as negros/ as (em 2010); resultados positivos na formação em Ensino Superior de jovens negros/as e na formação de professoras/es em Educação das Relações Étnico-Raciais (VICENTE, MARTINS, 2011). Outro artigo analisou políticas de discriminação positiva no Ensino Superior francês, com as políticas via território contribuindo para a diversidade étnica, social, cultural e territorial do Instituto, mas de forma limitada (SOUZA, 2012). Outro artigo afirma que as políticas afirmativas que aumentaram a entrada de estudantes de classes populares na universidade demandam ainda mais serviços de orientação profissional e psicologia escolar na educação superior (SAMPAIO, 2010). Um artigo analisa o SINAES - Sistema Nacional de Avaliação da Educação Superior e discute a necessidade de aprofundamento das estratégias de avaliação formativa então em curso, para que a avaliação ajudasse a superaras desigualdades acumuladas (FERRAZ, 2008). Finalmente um artigo apresenta relato de trajetória pessoal e racismo institucional a que esteve submetido o autor (SILVA, F., 2012). Uma única pesquisa em nosso universo analisou o tema das políticas afirmativas para graduandos com deficiência (SILVA, CYMROT, D'ANTINO, 2012) e focou as demandas dos docentes para atendimento a diferentes grupos de discentes com deficiência em duas universidades privadas.

\section{Temas emergentes e lacunas}

A pesquisa Educação e Relações Étnico-Raciais: o Estado da Arte definiu operar com o conceito de emergente de Santos (ano) que comporta diferentes 
aspectos. Um sentido é aquilo que emerge e que é particularmente importante para o contexto social e para o momento. Emergente tem também um sentido daquilo que é emergência, que tem potencial para responder às demandas das contradições e desigualdades sociais.

Um estudo que analisa o conjunto de universidades que adotavam políticas afirmativas naquele momento e a proposta de adotar um "índice de inclusão racial", o "coeficiente entre a proporção de vagas ofertadas para cota racial e a proporção de pretos de pardos na população" (DAFLON, FERES JÚNIOR, CAMPOS, 2013, p. 322). Interpretamos a proposta de um índice e a busca de padrão que possibilita a comparação entre diferentes estudos e universidades como um tema emergente na pesquisa sobre políticas afirmativas no Brasil. Muitas pesquisas focalizaram programas ou universidades específicas, mas faltou o diálogo com o contexto mais abrangente na maior parte dos estudos. As pesquisas de caráter mais geral possibilitam uma perspectiva mais ampla de análise que pode inclusive ajudar a orientar os estudos com foco localizado. Em especial a busca de construção de um indicador para analisar e comparar as diversas amostras de comunidades universitárias específicas é muito relevante para a temática. Uma pesquisa se dedicou a analisar as políticas de diversidade no "Governo Lula" e discutiu as inconstâncias, contradições e disputas internas nas políticas de diversidade e nas ações afirmativas desenvolvidas pelo MEC - Ministério de Educação no período (MOEHLECKE, 2009). Outro estudo de caráter mais abrangente analisa programas de políticas afirmativas presentes em 24 universidades correlacionando com grupos de pesquisa e produção de conhecimento nas universidades (SANTOS, 2011). As conclusões do estudo são que os programas de ação afirmativa: - representam forma rápida, eficiente e justa de promover a diversidade nas universidades e a igualdade étnico-racial na educação; - os programas de ação afirmativa e os grupos de pesquisa estabelecem uma relação de cooperação e complementaridade que deve ser fortalecida. Apontamos o caráter emergente desta conclusão sobre a relação dos grupos de pesquisa com a com os programas de ação afirmativa em relação ao potencial de produção de saberes emancipatórios a partir da cooperação identificada pelo estudo.

A temática da desigualdade racial na docência superior foi analisada em estudo partiu de uma busca por docentes negros nas universidades mais relevantes na produção científica no Brasil (CARVALHO, 2014) e aponta que: o ambiente do ensino superior é de extrema exclusão para a população negra, constituindo-se como espaço de segregação que aumenta na medida em que se ascende nas hierarquias acadêmicas. Os/as poucos/as docentes negros/as experimentam confinamento racial em suas instituições. O ambiente segregado contribui para a difusão de ideias e conceitos dos acadêmicos brancos de forma 
naturalizada, como se fossem válidos também para acadêmicos/as negros/as. Por exemplo, a valorização do "mito da democracia racial" que é defendido por muitos acadêmicos brancos e não encontra par nos acadêmicos negros. A condição racial, portanto, interfere nas teorias que são produzidas. A abertura da carreira de docência e pesquisa para negros/as e indígenas é imperiosa (CARVALHO, 2014).

Um ponto que interpretamos como emergente e que se relaciona tanto com esta análise, quanto com a execução de políticas afirmativas para negros/ as e indígenas na universidade brasileira é a participação dos coletivos sociais atendidos pelas políticas afirmativas nos processos de produção de conhecimento e a proposta que "um dos critérios para avaliação da excelência da produção acadêmica é sua vinculação com necessidades e anseios dos segmentos que compõem a sociedade, bem como suas repercussões na vida social" (SILVA, P., 2008, p. 42). Esta posição coincide com a análise que afirma que a participação de grupos historicamente silenciados, como negros e indígenas, são forma de resistência (OLIVEIRA, PROENÇA, CRUZ, 2014) e tem potencial de construção de cidadania e emancipação (MARCON, 2012).

Um outro ponto que interpretamos como emergente é a análise sobre as políticas afirmativas terem iniciado como demanda de igualdade racial e passaram a ser vinculadas especialmente com a classe social (XAVIER, XAVIER, 2009; SANTOS, SOUZA, SASAKI, 2012). A preponderância das políticas afirmativas com prioridade para classe em detrimento de raça tem sido pouco analisada. Lembremos a análise sobre a posição do jornal $O$ Globo citada anteriormente (VIENBRANTZ, CASONATTO, SOMERS, 2012), que passou de uma posição totalmente contrária para uma defesa de políticas afirmativas baseadas na classe social. Tal perspectiva passou a ser a mais difundida e se expressa na Lei 12.711/2012 que institui cotas para escola pública e o recorte racial como subcota, sendo, portanto, uma política de classe antes que de raça.

Um último ponto emergente é a interseccionalidade de raça com gênero, que em diversos estudos figura como simples intercruzamento de raça e gênero nos dados e tem como proposta de análise, desenvolvida de forma preliminar, no estudo de Cordeiro (2013). O mesmo artigo propõe a realização de estudos sobre egressos, especificamente sobre mulheres negras egressas de programas de ações afirmativas. A ausência de pesquisas sobre egressos é uma das lacunas no conjunto de artigos analisados.

Outra lacuna que observamos no conjunto de pesquisas é a falta de diálogo entre as pesquisas; as revisões estão ausentes, incompletas ou não têm relevância para a argumentação ou como fonte de comparação de dados. Alguns artigos apresentam revisão de estudos, mas mesmo estes pouco contrastam seus dados com os demais. Nos artigos que fazem o debate sobre as políticas de cotas, en- 
contramos alguns exemplos contrários, mas a tendência geral foi de apresentar os argumentos sem discutir com outros estudos. Nos estudos sobre casos específicos de universidades essa limitação se torna mais relevante, pois existem muitos estudos sobre universidades específicas que caso se apropriassem de critérios dos demais, facilitariam nas possibilidades para constituir visões mais abrangentes ou de generalização de resultados. Mesmos os diversos estudos que trataram de dados de desempenho nos cursos, a comparatibilidade de resultados é muito limitada. No caso de políticas de ingresso, de dados de rendimento, de políticas de permanência e mesmo de políticas de identidade adotadas em diferentes IES - Instituições de Ensino Superior, buscar algum nível de padronização pode ajudar a identificar variáveis outras (regiões, tipo de instituição, contexto local ou estadual, distribuição de raça/cor da população, perfil da comunidade, por exemplo) que ajudariam mais ao avanço do conhecimento disponível sobre o tema. No caso dos estudos que tratam com dados quantitativos, inicialmente tínhamos uma hipótese de poder realizar alguma meta-análise, mas, em vez de mínimo de padronização, observamos o máximo de pulverização nas abordagens, formas de coleta e dados.

Duas outras lacunas são a análise sobre políticas em outros espaços que não a graduação. O debate sobre cotas raciais para ingresso no ensino superior está muito difundido. Mas não encontramos qualquer artigo sobre políticas afirmativas na pós-graduação publicado em periódicos de educação entre 2003 e 2014. No caso da docência na Universidade, identificamos um único artigo (CARVALHO, 2014), numa discussão iniciada pelo próprio autor mas, pelo que indica o conjunto de artigos, pouco tem encontrado eco na pesquisa na área de educação.

\section{A título de conclusão}

Como síntese desta análise, vamos desenvolver dois pontos. O primeiro relaciona-se com o debate que observamos em artigos, muitos deles ensaios sem base empírica, que se posicionaram contrário às cotas para negros nas universidades:

a. o argumento que as "políticas racialistas" iriam resultar em conflitos raciais revelou-se uma conjectura sem nenhuma materialidade. Nenhum dos escritos que fizeram monitoramento de diferentes aspectos da política relatou qualquer incidente ou aumento de conflitos raciais nas universidades, assim como relatos deste tipo de conflito nas universidades são episódicos; 
b. outro argumento, que o necessário seria melhorar a educação básica de forma a dar a todos/as condições de igualdade também revelou-se inconsistente. No período entre 2003 e 2014, a educação básica apresentou, por um lado, faltas e lacunas, por outro, melhora constante no investimento e nos indicadores (por exemplo cobertura na educação infantil, ensino fundamental e ensino médio, taxas de escolarização líquida e bruta, média de anos de estudo). No ano de 2014 foi aprovado o PNE - Plano Nacional de Educação (Lei 13.005 de 25/06/2014) e as metas aprovadas projetavam significativos avanços em todas etapas e modalidades e com uma meta específica (Meta 8) de igualar a escolaridade média de brancos/as e negros/as. Em 2016, após o golpe que afastou a então presidenta, foi aprovada a restrição orçamentária que proíbe o aumento do investimento do governo em políticas sociais o que, na prática, inviabiliza o Plano Nacional de Educação e coloca a rota da qualidade da educação básica e dos indicadores educacionais no rumo de aumento das dificuldades e restrições. Olhando para os anos que se passaram desde o início do debate sobre cotas na universidade, temos a ampliação de qualidade da educação básica que não se refletiu de forma linear no ingresso de negros/as nas universidades e, caso não tivessem sido adotadas políticas afirmativas (cotas e PROUNI) a desigualdade entre negros/as e brancos/as no ensino superior teria continuado sua trajetória de aumento. Com a adoção das referidas políticas a desigualdade deixou de se ampliar, estabilizando. O monitoramento do PNE terá resultados mais relevantes, mas as projeções, com a diminuição de investimento na educação, são pessimistas. Ou seja, o argumento de resolver a desigualdade no Ensino Superior via a Educação Básica não se aproximou nos anos recentes e está em rota de tornar mais distante nos próximos anos. Assim como a ideia de que cotas para negros no ensino superior teriam algum efeito em diminuição de qualidade na Educação Básica ou Ensino Superior não tem nenhum dado ou estudo entre os examinados que as sustente;

c. relacionado com o argumento anterior estão as contradições entre raça e classe e a necessidade de promover políticas de igualdade de classe que deveriam ser o foco único ou mais importante (AZEVEDO, 2004; HERMIDA, 2004; LIMA, 2010A; 2010B; 2011; AGOSTINHO, BREGA FILHO, 2011). Os demais estudos analisados são pródigos em apresentar dados que refutam as posições expressas em tais artigos, tanto pelo manejo de dados sobre desigualdade étnico-racial no Brasil que sustentam a tese que a raça opera como eixo de desigualdade com algumas convergências, mas com particularidades e independência 
em relação à classe (GUIMARÃES, 2003; NEVES, 2003, 2005; MOEHLECKE, 2004; DOMINGUES, 2005; VALENTE, 2006; ANDRADE, DACHS, 2007; BELTRÃO, TEIXEIRA, 2008; RANGEL, 2008; OSORIO 2009; MARQUES, 2010; VELLOSO, 2010; AGOSTINHO, BREGA FILHO, 2011; MARCON, 2012; QUEIRÓZ, 2012; VIEIRA, 2012; SILVA FILHO, 2014); quanto pelo exame dos aspectos diversos (anteriormente apresentados), relativos ao desenvolvimento de políticas afirmativas no Brasil (CERRI, PLÁ, 2008; SILVA, P., 2008; BAKES, 2010; VELOSSO, CARDOSO, 2011; DOEBBER, GRISA, 2012; FERREIRA, TENÓRIO, 2012; HASS, LINHARES, 2012; OLIVEIRA, CONTARINE, CURY, 2012; SANTOS, 2012; SILVA, MOSCA, ZIMERMAM, 2012; VIENBRANTZ, CASONATTO, SOMERS, 2012; CORDEIRO, 2013; DAFLON, FERES JÚNIOR, CAMPOS, 2013; CARVALHO, 2014; HOLANDA, WELLER, 2014; ROSA, 2014).

O segundo ponto que acrescemos nesta conclusão é uma síntese de principais resultados dos estudos aqui analisados em diálogo com outros dois artigos de revisão de pesquisas sobre políticas afirmativas (SANTOS, 2012; CUNHA, SILVA FILHO, CUNHA, 2014).

A crítica levantada por Santos (2012) sobre estudos sobre políticas afirmativas no ensino superior que não apresentam recorte étnico-racial, ou seja, silenciam sobre a raça ou que tratam a desigualdade racial como epifenômeno da desigualdade de classe continuam presentes na literatura. No entanto, no conjunto de artigos sobre políticas afirmativas publicados na área de educação tem muito mais expressão a tese que raça e classe são dois eixos é "estrutural e estruturante" na sociedade brasileira. O conjunto de dados e as análises empreendidas nos diversos estudos sustenta a tese de que os indicadores sociais expressam a variável raça como determinante de acesso a bens sociais e à educação superior, e que as cotas raciais cumprem um papel de promover acesso a grupos historicamente discriminados (DOMINGUES, 2005; QUEIRÓZ E SANTOS, 2006; VALENTE, 2006; BELTRÃO E TEIXEIRA, 2008; SILVA, P., 2008; MOEHLECKE, 2009; MARQUES, 2010; VELLOSO, 2010; VELOSSO E CARDOSO, 2011; QUEIRÓZ, 2012; CORDEIRO, 2013; DAFLON, FERES JÚNIOR E CAMPOS, 2013; CARVALHO, 2014; HOLANDA E WELLER, 2014).

Nas sínteses realizadas por Santos (2012) e Cunha, Silva Filho e Cunha (2014, p. 84) encontramos alguns pontos em comum no conjunto de artigos analisados. De uma maneira geral, os estudos revelam crescimento na adoção de políticas afirmativas e no reconhecimento dos direitos de grupos sociais ao 
acesso à educação superior. Mesmo após a aprovação da Lei de cotas em 2012 que homogeneizou o sistema nas Universidades e Institutos Federais, existe uma variedade de modelos e programas que foram implementados e que estão sendo objeto de acompanhamento e monitoramento. Por um lado, os estudos não cobrem toda a diversidade e os diversos modelos adotados em universidades públicas (federais e especialmente nas estaduais e municipais) e privadas (com ou sem fins lucrativos; comunitárias, confessionais, filantrópicas). Por outro, há disponível um grande conjunto de estudos sobre diversos aspectos das políticas, especialmente sobre as políticas de acesso e seu impacto na entrada de negros/as no Ensino Superior. As avaliações realizadas oferecem dados relevantes para o monitoramento e aprimoramento das medidas adotadas. A literatura especializada revela que os movimentos sociais exerceram e exercem um papel relevante nos processos de produção, implementação e monitoramento das políticas.

O tema das políticas afirmativas na educação brasileira apresenta, nos artigos publicados em revistas da área de educação, um campo que foi crescente e com análises relevantes. Existem muitos campos a serem abordados pela pesquisa, em especial apontamos: as políticas afirmativas na pós-graduação e na docência (a exemplo do estudo de Carvalho, 2014); maior investimento em estudos sobre permanência, sobre mudanças nas universidades e políticas curriculares que acompanham as políticas afirmativas (como o Silva, P. 2008); de políticas de identidade (exemplos em Bakes, 2010; Holanda e Weller, 2014); estudos de abordagem mais geral ou sínteses (ver Daflon, Feres Júnior e Campos, 2013, especialmente sua proposta de "índice de inclusão racial").

Observou no conjunto de artigos, por um lado, um campo de conhecimento em construção na área de educação, num diálogo interdisciplinar com outras áreas das ciências humanas, notadamente a Sociologia e a Ciência Política, com um arcabouço de análises consistentes e relevantes. Por outro, as pesquisas se debruçaram sobre aspectos bastante determinados ou circunscritos, existindo uma série de facetas sobre ações afirmativas a serem melhor explorados pela pesquisa em educação.

\section{REFERÊNCIAS}

AGOSTINHO, L. O. V.; BREGA FILHO, V. Por um olhar democrático às ações afirmativas. Revista Brasileira de Estudos Pedagógicos, v. 92, n. 232, p. 455-476, 2011. Disponível em: $<$ http://www.rbep.inep.gov.br/index.php/rbep/article/view/662 $>$. Acesso em: 25 jul. 2017. 
AGRA, K. L. de O. A neutralização das discriminações por meio da educação da criança. Revista Brasileira de Estudos Pedagógicos [online], v. 93, n. 234, p. 612-626, 2012. Disponível em: <http://www.scielo.br/scielo.php?pid=S2176$-66812012000400005 \&$ script=sci_abstract\&tlng=pt>. Acesso em: 13 mar. 2017.

ANDRADE, C. Y. de; DACHS, J. N. W. Acesso à educação por faixas etárias segunda renda e raça/cor. Cadernos de Pesquisa, v. 37, n 131. p. 399-422, 2007. Disponível em: <http://www.scielo.br/pdf/cp/v37n131/a0937131.pdf > . Acesso em: 13 mar. 2017.

ARANHA, A. V. S. Programas de inclusão na UFMG: o efeito do Bônus e do REUNI nos quatro primeiros anos de vigência-um estudo sobre acesso e permanência. Educação em Revista, v. 28, n. 4, 2012. Disponível em: <http://submission.scielo.br/index.php/edur/ article/view/100103>. Acesso em: 13 mar. 2017.

ARAUJO, E. J. M.; CORRÊA, E. M. PROUNI: Políticas de inclusão ou exclusão no contexto das aprendizagens ao longo da vida. Revista Educação e Fronteiras On-Line, v. 1, n. 1, p. 32-47, 2011. Disponível em: <http://ojs.ufgd.edu.br/index.php/educacao/ article/view/1406>. Acesso em: 13 mar. 2017.

AZEVEDO, C. M. M. de. Cota racial e Estado: abolição do racismo ou direitos de raça? Cadernos de Pesquisa, v. 34, n. 121, p. 213-239, 2004. Disponível em: <http://www. scielo.br/pdf/cp/v34n121/a10n121.pdf>. Acesso em: 13 mar. 2017.

BACKES, J. L. Práticas multiculturais no ensino superior? A perspectiva dos acadêmicos afro-descendentes. Cadernos de Educação, v. 37, n. 93, p. 93-108, 2010. Disponível em: $<$ https://periodicos.ufpel.edu.br/ojs2/index.php/caduc/article/viewFile/1581/1467/>. Acesso em: 13 mar. 2017.

BELTRÃO, K. I.; TEIXEIRA, M. de P. O caminho de menor resistência: Escolhas no ensino superior brasileiro por cor/raça e gênero. Revista Educação Pública, v. 17, p. 315-332, 2008. Disponível em: <http://periodicoscientificos.ufmt.br/index.php/educacaopublica/article/view/535/456>. Acesso em: 13 mar. 2017.

BONILHA, T. P. Ações afirmativas e integração do negro no ensino superior: uma relação possível? Educação Temática Digital, v. 13, n. 1, p. 152-167, 2011. Disponível em: $<$ https://periodicos.sbu.unicamp.br/ojs/index.php/etd/article/view/1171/1186>. Acesso em 13 mar. 2017.

BOUSFIELD, A. B. S.; CAMARGO, B. V.; CASTRO, A.; KOELZER, L. P. Representações sociais na internet sobre cotas para negros em universidades federais. Cadernos de Pesquisa Interdisciplinar em Ciências Humanas, v. 15, n. 106, p. 202-220, 2014. Disponível em: <https://periodicos.ufsc.br/index.php/cadernosdepesquisa/article/ view/1984-8951.2014v15n106p202>. Acesso em: 13 mar. 2017.

BRAGA, M. M.; PEIXOTO, M. do C. de. L. Ações afirmativas no ensino superior e o programa de bônus para ingresso nos cursos de graduação da Universidade Federal de Minas Gerais. Revista Brasileira de Estudos Pedagógicos, v. 93, n. 233, p. 166-188, 2012. Disponível em: $<$ http://www.redeacaoafirmativa.ceao.ufba.br/uploads/inep_artigo_2012_MCLPeixoto_MMBraga.pdf>. Acesso em: 13 mar. 2017. 
BRANDÃO, A. A.; MARTINS, M. T. A. de. Cotas para negros no ensino superior e formas de classificação racial. Educação e Pesquisa, v. 33, n. 1, p. 27-45, 2007. Disponível em: <http://www.scielo.br/pdf/ep/v33n1/a03v33n1.pdf>. Acesso em: 13 mar. 2017.

BRASILEIRO, J. Ações afirmativas: políticas de inclusão. Revista de Educação Popular, v. 2, n. 1, p. 49-51, 2008. Disponível em: <http://www.seer.ufu.br/index.php/reveducpop/ article/view/20023>. Acesso em: 13 mar. 2017.

CARVALHO, J. J. de. O confinamento racial do mundo acadêmico brasileiro. Padê: Estudos em Filosofia, raça, gênero e direitos humanos (encerrada), v. 1, n. 1, 2007. Disponível em: <https://www.publicacoesacademicas.uniceub.br/pade/article/view/144>. Acesso em: 13 mar. 2017.

CASONATTO, O. D.; SOMERS, P.; VIEBRANTZ, R. Discurso da imprensa sobre ação afirmativa e formação de professores no Brasil. Cadernos de Pesquisa Pensamento Educacional, 2012.

CERRI, L. F.; PLÁ, S. Política de cotas na UEPG. Atos de Pesquisa em Educação, v. 3, n. 1, p. 3-19, 2008. Disponível em: <http://gorila.furb.br/ojs/index.php/atosdepesquisa/ article/view/797>. Acesso em: 13 mar. 2017.

CORDEIRO, A. L. A. Ações afirmativas na educação superior: mulheres negras cotistas e mobilidade social. Revista Pedagógica, v. 15, n. 30, p. 297-314, 2013. Disponível em: $<$ https://bell.unochapeco.edu.br/revistas/index.php/pedagogica/article/view/1572>. Acesso em: 13 mar. 2017.

CUNHA, E. O.; CUNHA, M. C.; FILHO, P. S. Direitos humanos e equidade: um olhar sobre as políticas de ações afirmativas na educação superior no Brasil. Revista Educação Online, n. 16, p. 66-89, 2014. Disponível em: <http://www.equidade.faced.ufba.br/sites/ equidade.oe.faced.ufba.br/files/acoes_afirmativas_eudes_penildon_maria_couto_educonline_puc-rio.pdf $>$. Acesso em: 13 mar. 2017.

DAFLON, V. T.; FERES JÚNIOR, J.; CAMPOS, L. A. Ações afirmativas raciais no ensino superior público brasileiro: um panorama analítico. Caderno de Pesquisa, v. 43, n. 148 p. 302-327, 2013. Disponível em: <http://www.scielo.br/pdf/cp/v43n148/15.pdf $>$. Acesso em: 13 mar. 2017.

DOEBBER, M. B.; GRISA, G. D. Ações afirmativas: o critério racial e a experiência da Universidade Federal do Rio Grande do Sul. Revista Brasileira de Estudos Pedagógicos, v. 92, n. 232, 2011. Disponível em: <http://rbep.inep.gov.br/index.php/rbep/article/ view/668>. Acesso em: 13 mar. 2017.

DOMINGUES, P. Ações afirmativas para negros no Brasil: o início de uma reparação histórica. Revista ANPED, n. 29 p. 164-176, 2005. Disponível em: <http://www.scielo. br/pdf/rbedu/n29/n29a13>. Acesso em: 13 mar. 2017.

FERRAZ, B. T. Ações afirmativas e cultura da avaliação: o Programa Conexões de Saberes em questão. Revista África e Africanidades, ano 2, n. 6, 2009. Disponível em: $<$ http:// 
www.africaeafricanidades.com.br/documentos/Acoes_afirmativas_e_cultura_da_avaliacao_Programa_Conexoes_de_Saberes_em_questao.pdf $>$. Acesso em: 13 mar. 2017.

FERRAZ, B. T. Função social da universidade e políticas de ação afirmativas no Brasil: elementos para discussão sob o prisma da avaliação institucional. Revista África e Africanidades, v. 1, n. 2, 2008. Disponível em: < http://africaeafricanidades.com.br/documentos/ Funcao_social_da_universidade.pdf>.Acesso em: 13 mar. 2017.

FERREIRA, R. A.; TENÓRIO, R. M. Políticas institucionais de equidade e pertinência social na Universidade Federal da Bahia. Poiésis-Revista do Programa de Pós-Graduação em Educação, v. 5, p. 201-215, 2012. Disponível em: <http://www.portaldeperiodicos. unisul.br/index.php/Poiesis/article/view/1174>. Acesso em: 13 mar. 2017.

FISCHMAN, G. E.; SALES, S. R. Reduções, confusões e más intenções: avançando na compreensão das políticas de ação afirmativa no ensino superior brasileiro. Revista Teias, v. 9, n. 17, p. 47-58, 2008. Disponível em: <http://www.e-publicacoes.uerj.br/ index.php/revistateias/article/view/24026>. Acesso em: 13 mar. 2017.

GUIMARÃES, A. S. A. Acesso de negros às Universidades públicas. Cadernos de Pesquisa, n. 118, p. 247-268, março 2003. Disponível em: < http://www.scielo.br/pdf/ cp/n118/16836.pdf>. Acesso em: 13 mar. 2017.

HAAS, C. M.; LINHARES, M. Políticas públicas de ações afirmativas para ingresso na educação superior se justificam no Brasil? Rev. Bras. Estud. Pedagógicos, v. 93, n. 235, p. 836-863, dez. 2012. Disponível em: <http://www.emaberto.inep.gov.br/index.php/ rbep/article/view/418>. Acesso em: 13 mar. 2017.

HERMIDA, J. F. A Política de Ações Afirmativas (PAA) e a inclusão educacional nas universidades brasileiras. Revista de Ciências da Educação, 2004. Disponível em: $<$ http:// www.anped11.uerj.br/27/Jorge\%20Hermida.rtf>. Acesso em: 13 mar. 2017.

HOLANDA, M. A. G. de; WELLER, W. Trajetórias de vida de jovens negras da Universidade de Brasília no Contexto das Ações Afirmativas. Poiésis-Revista do Programa de Pós-Graduação em Educação, v. 8, n. 13, p. 57-80, 2014. Disponível em: <http://portaldeperiodicos.unisul.br/index.php/Poiesis/article/view/2170>. Acesso em: 13 mar. 2017.

JULIO, A. L. dos S.; STREY, M. N. Negros e negras no ensino superior: singularidade para a permanência. Revista África e Africanidades, ano 2, n. 5 p. 19-51, 2009. Disponível em: <http://www.africaeafricanidades.com.br/documentos/Negros_e_Negras_no $\% 20$ ensino_superior_singularidade_para_permanencia.pdf>. Acesso em: 13 mar. 2017.

KERN, G. da S. Questão racial, ações afirmativas e currículo: uma discussão em torno das diretrizes para a educação das relações étnico-raciais. Revista Linhas, v. 15, n. 28, p. 324-344, 2014. Disponível em: <http://www.periodicos.udesc.br/index.php/linhas/ article/view/1984723815282014324>. Acesso em: 13 mar. 2017.

LAREAU, A. A desigualdade invisível: o papel da classe social na criação dos filhos em famílias negras e brancas. Educação em Revista, n. 46, p. 13-82, 2007. Disponível em: $<$ http://www.scielo.br/pdf/edur/n46/a02n46.pdf>. Acesso em: 13 mar. 2017. 
LIMA, M. das G. de; NEVES, P. D. M.; SANTOS, A. D. dos. Onde estão os alunos negros da Universidade Estadual de Maringá (PR)? Revista da ABPN, v. 3, n. 7, p. $117-$ 127, 2012. Disponível em: <http://www.academia.edu/download/31311417/Onde_estao_os_alunos_negros_da_UEM.pdf $>$. Acesso em: 13 mar. 2017.

LIMA, P. G. Ações afirmativas e universidade no Brasil. Revista HISTEDBR On-line, v. 10, n. 39, 2010a. Disponível em: <https://www.fe.unicamp.br/revistas/ged/histedbr/ article/view/3411>. Acesso em: 13 mar. 2017.

LIMA, P. G. Universidade Brasileira: para além das políticas de ações afirmativas. Educação em Perspectiva, v. 1, n. 2, p. 177-197, 2010b. Disponível em: <http://www. seer.ufv.br/seer/educacaoemperspectiva/index.php/ppgeufv/article/view/34>. Acesso em: 13 mar. 2017.

LIMA, P. G. A Universidade no Brasil e Políticas de Ações Afirmativas. Revista HISTEDBR On-Line, v. 11, n. 44, p. 156-170, 2011. Disponível em: <http://www.histedbr. fe.unicamp.br/revista/edicoes/44/art10_44.pdf>. Acesso em: 13 mar. 2017.

LIMA, M. E. O.; NEVES, P. S. da C.; SILVA, P. B. A implantação de cotas na universidade: paternalismo e ameaça à posição dos grupos dominantes. Revista Brasileira de Educação, v. 19, n. 56, 2014. Disponível em: <http://www.redalyc.org/html/275/27530123008>. Acesso em: 13 mar. 2017.

MACIEL, R. O. Ações afirmativas na Universidade Federal do Maranhão. Revista Brasileira de Estudos Pedagógicos, v. 93, n. 233, 2012. Disponível em: <http://rbep.inep. gov.br/index.php/RBEP/article/view/1995/1789>. Acesso em: 13 mar. 2017.

MAGGIE, Y. Racismo e anti-racismo: preconceito, discriminação e os jovens estudantes nas escolas cariocas. Educação \& Sociedade, v. 27, n. 96, p. 739-751, 2006. Disponível em: <http://www.scielo.br/pdf/es/v27n96/a06v2796.pdf>. Acesso em: 13 mar. 2017.

MARCON, T. Políticas de ação afirmativa no contexto da sociedade brasileira. Revista Brasileira de Estudos Pedagógicos, v. 93, n. 233, p. 11-33, 2012. Disponível em: <http:// emaberto.inep.gov.br/index.php/rbep/article/view/457>. Acesso em: 13 mar. 2017.

MARQUES, C. E. Ações afirmativas: uma necessidade plural e multicultural para a educação. Revista Africa e Africanidades, ano 3, n. 10, 2010. Disponível em: <http://www. africaeafricanidades.com.br/documentos/01112010_08.pdf>. Acesso em: 13 mar. 2017.

MARQUES, E. P. de S. Políticas públicas de promoção da igualdade racial: onde chegamos, aonde queremos chegar? Educação e Fronteiras On-Line, v. 3, n. 6, p. 81-102, 2012. Disponível em: <http://ojs.ufgd.edu.br/ojs/index.php/educacao/article/view/2002>. Acesso em: 13 mar. 2017.

MARQUES, E. P. de S.; MAIA, S. F. Ações afirmativas e a política de cotas: uma análise do Programa Universidade para Todos - PROUNI - A inserção de negros na universidade. Série-Estudos - Periódico do Programa de Pós-Graduação em Educação da UCDB, n. 22, p. 47-59, 2016. Disponível em: <http://www.serie-estudos.ucdb.br/index.php/serie-estudos/article/view/274>. Acesso em: 13 mar. 2017. 
MARTINS, T. C. da S. Experiências do protagonismo da juventude negra na Faculdade Zumbi dos Palmares. Educação \& Linguagem, v. 14, n. 23/24, p. 57-74, 2011. Disponível em: $<$ https://www.metodista.br/revistas/revistas-ims/index.php/EL/article/view/2910>. Acesso em 13 mar. 2017.

MENDES JÚNIOR, A. A. F. Uma análise da progressão dos alunos cotistas sob a primeira ação afirmativa brasileira no ensino superior: o caso da Universidade do Estado do Rio de Janeiro. Revista Ensaio, v. 22, n. 82, p. 31-56, 2014. Disponível em: <http://www. scielo.br/pdf/ensaio/v22n82/a03v22n82.pdf>. Acesso em: 13 mar. 2017.

MOEHLECKE, S. Ação Afirmativa no Ensino Superior: entre a excelência e a justiça racial. Educação \& Sociedade, v. 25, n. 88, p. 757-776, 2004. Disponível em: <http:// www.scielo.br/pdf/es/v25n88/a06v2588.pdf>. Acesso em: 13 mar. 2017.

MOEHLECKE, S. As políticas de diversidade em educação no Governo Lula. Cadernos de Pesquisa, v. 39, n. 137, p. 461-487. Disponível em: <http://www.scielo.br/pdf/cp/ v39n137/v39n137a08.pdf>. Acesso em: 13 mar. 2017.

NAIFF, L. A. M.; NAIFF, D. G. M.; LOUBACK, E. Representações sociais das cotas raciais em duas universidades públicas do Estado do Rio de Janeiro: um estudo comparativo. Revista Educação e Cultura Contemporânea, v. 10, n. 20, p. 50-77, 2013. Disponível em: $<$ http://revistaadmmade.estacio.br/index.php/reeduc/article/viewArticle/405>. Acesso em: 13 mar. 2017.

NEGRÃO, M.; SILVA, S. R. Normatividade, políticas públicas educacionais e a questão racial no Brasil. Revista Brasileira de Estudos Pedagógicos, v. 93, n. 235, p. 864-882, 2012. Disponível em: <http://emaberto.inep.gov.br/index.php/rbep/article/view/419>. Acesso em: 13 mar. 2017.

NEVES, G. Cotas para negros na estratégia de inclusão social na universidade. Revista de Educação Popular, v. 2, n. 1, p. 40-44, 2003. Disponível em: <http://www.seer.ufu. br/index.php/reveducpop/article/view/20021>. Acesso em: 13 mar. 2017.

NEVES, G. A discriminação racial na Educação Brasileira. Revista de Educação Popular, v. 4, n. 1, p. 43-53, 2005. Disponível em: <http://www.seer.ufu.br/index.php/reveducpop/ article/download/19913/10635>. Acesso em: 13 mar. 2017.

OLIVEIRA, E. I. I.; MOLINA, R. M. Revista Brasileira de Estudos Pedagógicos, v. 93, n. 235, p. 667-697, 2012. Disponível em: <http://www.scielo.br/pdf/rbeped/v93n235/11. pdf>. Acesso em: 13 mar. 2017.

OLIVEIRA, M. A. M.; CONTARINE, M. L. M.; CURY, C. R. J. PROUNI: Análise de uma política pública no âmbito da PUC Minas. Revista Brasileira de Política e Administração da Educação, v. 28, n. 1, p. 48-6, 2012. Disponível em: <http://seer.ufrgs.br/ index.php/rbpae/article/view/36070/23317>. Acesso em: 13 mar. 2017.

OLIVEIRA, N. A.; PROENÇA, K. A. P.; CRUZ, J. B. da. Cotas raciais como forma de resistência: um enfoque freiriano. Revista Contexto \& Educação, v. 29, n. 92, p. 91-108, 
2014. Disponível em: < https://www.revistas.unijui.edu.br/index.php/contextoeducacao/ article/view/2975>. Acesso em: 13 mar. 2017.

OLIVEN, A. C. Ações afirmativas, relações raciais e política de cotas nas universidades: uma comparação entre os Estados Unidos e o Brasil. Revista Educação, n. 1, p. 29-51, 2007. Disponível em: <http://www.redeacaoafirmativa.ceao.ufba.br/uploads/pucrs_artigo_2007_ACOliven.pdf. Acesso em: 13 mar. 2017.

OSÓRIO, R. G. Classe, raça e acesso ao Ensino Superior no Brasil. Cadernos de Pesquisa, v. 39, n. 138, p. 867-880, 2009. Disponível em: <http://www.scielo.br/pdf/cp/v39n138/ v39n138a09.pdf>. Acesso em: 13 mar. 2017.

PERES, M. A. de C.; SOUZA, A. C. de. O Programa Conexões de Saberes como política afirmativa no contexto do semiárido nordestino: o caso da UFERSA em Mossoró/RN. Revista HISTEDBR On-Line, v. 12, n. 47, p. 297-313, 2012. Disponível em: <http:// periodicos.sbu.unicamp.br/ojs/index.php/histedbr/article/view/8640053>. Acesso em: 13 mar. 2017.

PIOVESAN, F. Ações afirmativas na perspectiva dos Direitos Humanos. Cadernos de Pesquisa. v. 35, n. 124, p. 43-55, 200. Disponível em: <http://www.scielo.br/pdf/cp/ v35n124/a0435124.pdf>. Acesso em: 13 mar. 2017.

PINEZI, A. K. M.; SILVA, S. J.; ZIMERMAN, A. Ações afirmativas e inclusão regional: a experiência da Universidade Federal do ABC. Revista Brasileira de Estudos Pedagógicos, v. 93, n. 233, p. 147-165, 2012. Disponível em: <http://www.redeacaoafirmativa. ceao.ufba.br/uploads/inep_artigo_2012_SJSilva_AKMPinezi_AZimermam.pdf $>$ Acesso em: 13 mar. 2017.

QUEIROZ, D. M. As políticas de cotas para negros nas universidades brasileiras e a posição dos intelectuais. Revista Pedagógica, v. 14, n. 28, p. 355-336, 2012. Disponível em: <http://bell.unochapeco.edu.br/revistas/index.php/pedagogica/article/view/1371>. Acesso em: 13 mar. 2017.

QUEIROZ, D. M.; SANTOS, J. T. Sistema de cotas: um debate. Dos dados à manutenção de privilégio e de poder. Educação \& Sociedade, v. 27, n. 96, p. 717-737, 2006. Disponível em: <http://www.scielo.br/pdf/es/v27n96/a05v2796.pdf>. Acesso em: 13 mar. 2017.

RABELLO, S. H. dos S. A igualdade em construção: políticas de ação afirmativa para inclusão de negros no ensino superior público brasileiro. Instrumento-Revista de Estudo e Pesquisa em Educação, v. 10, p. 87-98, 2008. Disponível em: <http://www. redeacaoafirmativa.ceao.ufba.br/uploads/ufjf_artigo_2008_SHdosRabello.pdf $>$.Acesso em: 13 mar. 2017.

RAIMUNDO, R. L. G.; TRAVITZKI, R. Alunos cotistas e atividades extracurriculares: análise do Censo da Educação Superior 2009. Revista Brasileira de Estudos Pedagógicos, v. 93, n. 233, p. 77-95, 2012. Disponível em: <http://www.emaberto.inep.gov.br/index. php/rbep/article/view/460>. Acesso em: 13 mar. 2017. 
RANGEL, M. Educación universitaria en Brasil. Desigualdades raciales y políticas de acción afirmativa para su combate. Revista África e Africanidades, ano 1, n. 1, 2008. Disponível em: $<\mathrm{http}: / /$ africaeafricanidades.com.br/documentos/Educacion_Universitaria_en_Brasil.pdf $>$. Acesso em: 13 mar. 2017.

ROSA, C. de M. Políticas Afirmativas para acesso à Educação Superior Brasileira: História e Embates. Plures Humanidades, v. 15, n. 1, 2014. Disponível em: <http:// seer.mouralacerda.edu.br/index.php/plures/article/view/111>. Acesso em: 13 mar. 2017.

SAMPAIO, S. M. R. A Psicologia na educação superior: ausências e percalços. Psicologia Escolar: Pesquisa e Intervenção, v. 23, n. 83, p. 95-105, 2010. Disponível em: $<$ http://rbep.inep.gov.br/index.php/emaberto/issue/viewFile/246/86\#page=95>. Acesso em: 13 mar. 2017.

SANTOS, A. de O. dos. Panorama dos programas de ação afirmativa para inserção da população negra no ensino público superior brasileiro (2002-2007): estudos e grupos de pesquisa. Revista da ABPN, v. 2, n. 5, p. 99-114, 2011. Disponível em: <https://www. researchgate.net/profile/Alessandro_Oliveira_Dos_Santos/publication/283350026_Panorama_dos_Programas_de_Acao_Afirmativa_para_Insercao_da_Populacao_Negra no_Ensino_Publico_Superior_Brasileiro_2002-2007_Estudos_e_Grupos_de_Pesquisa/ links/56362f7708ae75884114df21.pdf>. Acesso em: 13 mar. 2017.

SANTOS, C. T. Ações afirmativas no ensino superior: análise do perfil socioeconômico e da experiência universitária de bolsistas do ProUni na PUC-Rio. Revista Brasileira de Estudos Pedagógicos, v. 93, n. 235, p. 577-598, 2013. Disponível em: <http://rbep.inep. gov.br/index.php/RBEP/article/view/2028/1866>. Acesso em: 13 mar. 2017.

SANTOS, H.; SOUZA, M. G.; SASAKI, K. O subproduto social advindo das cotas raciais na educação superior do Brasil. Revista Brasileira de Estudos Pedagógicos, v. 94, n. 237, p. 542-563, ago. 213. Disponível em: <http://www.scielo.br/pdf/rbeped/v94n237/ a10v94n237.pdf>. Acesso em: 13 mar. 2017.

SANTOS, J. T. Ações afirmativas e educação superior no Brasil: um balanço crítico da produção. Revista Brasileira de Estudos Pedagógicos, v. 93, n. 234, p. 401-422, 2012. Disponível em: <http://rbep.inep.gov.br/index.php/RBEP/article/viewFile/2687/1830>. Acesso em; 13 mar. 2017.

SANTOS, N. N. da S. Água e azeite: políticas afirmativas e a democracia racial no Brasil. Revista Africa e Africanidades, ano 3, n. 11, 2010. Disponível em: <http://www. africaeafricanidades.com.br/documentos/01112010_08.pdf >. Acesso em: 13 mar. 2017.

SANTOS, P. C. M. de. A.; FERREIRA, R. A. Segregação, raça, cor e políticas de cotas nas universidades brasileiras: breves reflexões. Poiésis-Revista do Programa de Pós-Graduação em Educação, v. 5, p. 283-303, 2012. Disponível em: <http://www.portaldeperiodicos.unisul.br/index.php/Poiesis/article/view/1178>. Acesso em: 13 mar. 2017.

SILVA, A. M.; CYMROT, R.; D'ANTINO, M. E. F. Demandas de docentes do Ensino Superior para a formação de alunos com deficiência. Revista Brasileira de Estudos Pe- 
dagógicos, v. 93, n. 235, p. 667-697, 2012. Disponível em: <http:/www.scielo.br/pdf/ rbeped/v93n235/08.pdf>. Acesso em: 13 mar. 2017.

SILVA FILHO, P. A democratização da universidade brasileira por meio das cotas. Práxis Educacional, v. 10, n. 16, p. 199-219, 2014. Disponível em: <http://periodicos.uesb.br/ index.php/praxis/article/viewFile/2898/2580>. Acesso em: 13 mar. 2017.

SILVA, F. C. C. Racismo à brasileira: quanto vale ou é por quilo? Práxis Educacional, v. 8, n. 13, p. 281-291, 2012. Disponível em: < http://periodicos.uesb.br/index.php/praxis/ article/view/1592>. Acesso em: 13 mar. 2017.

SILVA, I. S. da. A Trajetória dos Estudos sobre Relações Raciais no Brasil. Padê: Estudos em Filosofia, raça, gênero e direitos humanos (encerrada), v. 1, n. 1, 2007. Disponível em: <https:/www.rbpp.uniceub.br/pade/article/view/145>. Acesso em: 13 mar. 2017.

SILVA, L. F. M. da. Apontamentos sócio-jurídicos sobre o tema "políticas públicas de ação afirmativa para negros no Brasil". Revista da Associação Brasileira de Pesquisadores/ as Negros/as (ABPN), v. 1, n. 2, p. 217-244, 2010. Disponível em: <http://www.abpnrevista.org.br/revista/index.php/revistaabpn1/article/view/298>. Acesso em: 13 mar. 2017.

SILVA, L. F. M. da. Políticas de ação afirmativas para negros no Brasil: Considerações sobre a compatibilidade com o ordenamento jurídico nacional e internacional. Revista Jurídica da Presidência, v. 8, n. 82, p. 64-83, 2007. Disponível em: <https://revistajuridica.presidencia.gov.br/index.php/saj/article/view/354>. Acesso em: 13 mar. 2017.

SILVA, M. L. da. Considerações sobre o dilema entre cor/raça/mestiçagem e ações afirmativas no Brasil. Reflexão e Ação, v. 18, n. 1, p. 8-29, 2010. Disponível em: <http:// online.unisc.br/seer/index.php/reflex/article/view/1441 >. Acesso em: 13 mar. 2017.

SILVA, P. B. G. e. Ações afirmativas na UFSCar - Em busca da qualidade acadêmica com compromisso social. Políticas Educativas, v. 2, n. 1, p. 41-53, 2008. Disponível em: <http://www.seer.ufrgs.br/Poled/article/view/18350>. Acesso em: 13 mar. 2017.

SOUZA, A. de M. Ações Afirmativas na Universidade Pública: comparação entre o sistema de cotas e o sistema de bônus. Revista Meta: Avaliação, v. 4, n. 12, p. 277-288, 2013. Disponível em: $<$ http://revistas.cesgranrio.org.br/index.php/metaavaliacao/article/ view/153>. Acesso em 13 mar. 2017.

SOUZA, D. N. de; BITTAR, M. Política de educação superior e os programas de permanência para universidades públicas-2003-2010. Série-Estudos - Periódico do Programa de Pós-Graduação em Educação da UCDB, n. 35, p. 199-217, 2013. Disponível em: $<$ http://www.serie-estudos.ucdb.br/index.php/serie-estudos/article/view/31>. Acesso em: 13 mar. 2017.

SOUZA, J. A. de. As políticas de discriminação positiva e a democratização das grandes escolas francesas. Revista Brasileira de Estudos Pedagógicos, v. 93, n. 233, p. 231-254, 2012. Disponível em: <http://emaberto.inep.gov.br/index.php/rbep/article/view/468>. Acesso em: 13 mar. 2017. 
TAFURI, D. M. As Ações Afirmativas e o Campo Científico: dilemas políticos e epistemológicos para a constituição de uma ciência social crítica. Políticas Educativas, v. 5, n. 1, p. 45-58, 2011. Disponível em: <http://www.seer.ufrgs.br/Poled/article/view/35732>. Acesso em: 13 mar. 2017.

TRAGTENBERG, M. H. R.; BASTOS; J. L. D.; NOMURA, L., H.; PERES, M A. Como aumentar a proporção de estudantes negros na Universidade? Cadernos de Pesquisa, v. 36, n. 128, p. 473-495, 2006. Disponível em: <http://www.scielo.br/pdf/cp/v36n128/ v36n128a10.pdf>. Acesso em: 13 mar. 2017.

VALENTE, A. L. E. F. A "má vontade antropológica" e as cotas para negros nas universidades (ou usos e abusos da antropologia na pesquisa educacional II: quando os antropólogos desaprendem). InterMeio: Revista do Programa de Pós-Graduação em Educação - UFMS, v. 12, n. 24, p. 84-103, 2006. Disponível em: <http://seer.ufms.br/ ojs/index.php/intm/article/view/2557>. Acesso em: 13 mar. 2017.

VELLOSO, J. Cotistas e não-cotistas: rendimento de alunos da Universidade de Brasília. Cadernos de Pesquisa, v. 39, n. 137, p. 621-644, 2009. Disponível em: <http://www. scielo.br/pdf/cp/v39n137/v39n137a14.pdf>. Acesso em: 13 mar. 2017.

VELLOSO, J. R. Traços de um percurso: ensino público, pós-graduação e ações afirmativas. Linhas Críticas, v. 17, n. 32, p. 187-196, 2011. Disponível em: <http://www. redalyc.org/html/1935/193519170014/>. Acesso em: 13 mar. 2017.

VELLOSO, J.; CARDOSO, C. B. Um quinquênio de cotas: as chances de ingresso de negros na Universidade de Brasília. Revista Brasileira de Estudos Pedagógicos, v. 92, n. 231, p. 221-245, 2011. Disponível em: <http://www.rbep.inep.gov.br/index.php/rbep/ article/view/527>. Acesso em: 13 mar. 2017.

VIEIRA, C. S. Cotas nas universidades: um grande debate público. ComCiência, n. 135,2012 . Disponível em: <http://comciencia.scielo.br/scielo.php?script=sci arttext\&pid=S1519-76542012000100007\&lng=en\&nrm=iso > . Acesso em: 13 mar. 2017.

VITORINO, D. da C. Quem precisa de Educação Anti-Racista? Uma discussão sobre o papel dos professores no combate ao racismo e a discriminação em sala de aula. Revista Teias, v. 12, n. 26, p. 131-142, 2011. Disponível em: <http://www.e-publicacoes.uerj.br/ index.php/revistateias/article/view/24215>. Acesso em: 13 mar. 2017.

WIELEWICK, H. de G.; OLIVEIRA, M. R. Ações afirmativas na UFRGS: opiniões em comunidades do Orkut. Políticas Educativas, v. 1, n. 2, p. 88-104, 2008. Disponível em: <http://www.seer.ufrgs.br/Poled/article/view/18303>. Acesso em: 13 mar. 2017.

XAVIER, E. D.; XAVIER, S. P. Políticas de Ação Afirmativa e Relações Raciais no Brasil e nos Estados Unidos. Desenvolvimento em Questão, v. 7, n. 14, p. 43-87, 2009. Disponível em: $<$ https://www.revistas.unijui.edu.br/index.php/desenvolvimentoemquestao/article/view/173>. Acesso em: 13 mar. 2017.

ZUCCHETTI, D.; KLEIN, M.; SABAT, R. T. Marcas das diferenças nas políticas de inclusão social. Educação e Realidade, v. 32, n. 1, p. 75-90, 2007. Disponível em: 
$<$ http://seer.ufrgs.br/index.php/educacaoerealidade/article/view/6661/3977>. Acesso em: 13 mar. 2017.

\section{Teses e Dissertações analisadas}

AGOSTINHO, K. M. O estudante beneficiado por programas de ação afirmativa do curso de Enfermagem da Universidade Federal do Mato Grosso Campus Universitário de Sinop: quem sou eu? Quem é ele? 2015. 132 f. Dissertação (Mestrado em Educação) - Programa de Pós-Graduação em Educação, Universidade Federal do Mato Grosso, Cuiabá, 2015. Disponível em: <http://ri.ufmt.br/handle/1/162>. Acesso em: 25 jul. 2017.

ALMEIDA, M. A. O. Políticas de ação afirmativa e ensino superior: a experiência do curso de graduação em serviço social da PUC-RIO. 2003. 130 f. Dissertação (Mestrado em Educação) - Departamento de Educação, Pontifícia Universidade Católica do Rio de Janeiro, Rio de Janeiro, 2003. Disponível em: <https://www.maxwell.vrac.puc-rio. br/Busca_etds.php?strSecao=resultado\&nrSeq=4312@1>. Acesso em: 25 jul. 2017.

ANCHIETA, K. de A. História da implantação do sistema de cotas para negros da Universidade de Londrina (UEL). 2008. 144 f. Dissertação (Mestrado em Educação) - Programa de Pós-Graduação em Educação, Universidade Estadual de Londrina, Londrina, 2008. Disponível em: <http://www.uel.br/pos/mestredu/images/stories/downloads/ dissertacoes/2008/2008\%20-\%20ANCHIETA,\%20Karen\%20de\%20Abreu.pdf $>$. Acesso em: 25 jul. 2017.

ARBACHE, A. P. R. B. A política de cotas raciais na universidade pública brasileira: um desafio ético. 2008. 281 f. Tese (Doutorado em Educação - Currículo) - Pontifícia Universidade Católica de São Paulo, São Paulo, 2008. Disponível em: <http://www. redeacaoafirmativa.ceao.ufba.br/uploads/pucsp_tese_2006_APRBArbache.pdf $>$.Acesso em: 25 jul. 2017.

AVILA, M. M. O significado das cotas para estudantes negros do Instituto Federal de Santa Catarina: Campus São José. 2012. 122 f. Dissertação (Mestrado em Educação) - Faculdade de Educação, Universidade Estadual de Campinas, Campinas, 2012. Disponível em: $<$ http://repositorio.unicamp.br/jspui/handle/REPOSIP/250867>. Acesso em: 25 jul. 2017.

BACCHETTO, J. G. Cursinhos pré-vestibulares alternativos no município de São Paulo (1991-2000): a luta pela igualdade no acesso ao ensino superior. 2003. 170 f. Dissertação (Mestrado em Educação) - Faculdade de Educação, Universidade de São Paulo, São Paulo, 2003. Disponível em: <http://www.teses.usp.br/teses/disponiveis/48/48134/tde07082003-114804/pt-br.php>. Acesso em: 25 jul. 2017.

BALBINO, A. B. O caráter democrático das ações afirmativas: considerações sobre os impactos sociais da implementação das políticas de cotas na UERJ e suas possíveis contribuições ao processo de democratização do ensino no Brasil. 2004. 192 f. Dissertação (Mestrado em Educação) - Programa de Pós-Graduação em Educação, Universidade do 
Estado do Rio de Janeiro, Rio de Janeiro, 2004. Disponível em: <http://www.proped. pro.br/teses/teses_pdf/Antonio_Berbardino_Baldino.pdf $>$. Acesso em: 25 jul. 2017.

BARBOSA, V. A. Politicas de democratização da educação superior: análise do programa de integração e de inclusão étnico-racial da UNEMAT - PIIER/UNEMAT (2005/2 A 2011/1). 2013. 160 f. Dissertação (Mestrado em Educação) - Programa de Pós-Graduação em Educação, Universidade Federal do Mato Grosso, Cuiabá, 2013. Disponível em: $<$ http://www.unemat.br/prppg/educacao/docs/dissertacao/2013/valci_aparecida_barbosa. pdf $>$. Acesso em 25 jul. 2017.

BARRETO, L. A. Pela graça da mistura: ações afirmativas, discurso e identidade negra no curso de direito em universidades públicas paraibanas. 2014. 202 f. Tese (Doutorado em Educação) - Programa de Pós-Graduação em Educação, Universidade Federal da Paraíba, João Pessoa, 2014. Disponível em: < http://tede.biblioteca.ufpb.br:8080/handle/ tede/4784>. Acesso em: 25 jul. 2017.

BELLO, L. Politica de ações afirmativas na UFRGS: o processo de resiliência na trajetória de vida de estudantes cotistas negros com bom desempenho acadêmico. 2011. 141 f. Dissertação (Mestrado em Educação) - Programa de Pós-Graduação em Educação, Universidade Federal do Rio Grande do Sul, Porto Alegre, 2011. Disponível em: $<$ http:// www.lume.ufrgs.br/bitstream/handle/10183/35089/000793573.pdf?sequence=1>. Acesso em: 25 jul. 2017.

CAMARGO, E. P. R. O negro na educação superior: perspectivas das ações afirmativas. 2005. 212 f. Tese (Doutorado em Educação) - Programa de Pós-Graduação em Educação, Universidade Estadual de Campinas, Campinas, 2005. Disponível em: <http://www. bdae.org.br/dspace/bitstream/123456789/1723/1/tese.pdf>. Acesso em: 25 jul. 2017.

CARDOSO, C. B. Efeitos da política de cotas na Universidade de Brasília: uma análise do rendimento e da evasão. 2008. 134 f. Dissertação (Mestrado em Educação) - Programa de Pós-Graduação em Educação, Faculdade de Educação, Universidade de Brasília, Brasília, 2008. Disponível em: <http://repositorio.unb.br/bitstream/10482/1891/1/2008_ClaudeteBatistaCardoso.pdf>. Acesso em: 25 jul. 2017.

CASTRO, L. A. de. Politica de cotas para negros na Universidade Estadual de Mato Grosso do Sul-UEMS - Unidade Aquidauana: a percepção dos alunos cotistas e professores. 2008. 143 f. Dissertação (Mestrado em Educação) - Programa de Pós-Graduação em Educação, Universidade Católica Dom Bosco, Campo Grande, 2008. Disponível em: $<$ http://site.ucdb.br/public/md-dissertacoes/8033-politica-de-cotas-para-negros-na-universidade-estadual-de-mato-grosso-do-sul-uems-unidade-aquidauana-a-percepcao-dos-alunos-cotistas-e-professores.pdf>. Acesso em: 25 jul. 2017.

CONSTÂNCIO, J. O negro e as politicas de ação afirmativa no contexto da desigualdade educacional. 2009. 105 f. Dissertação (Mestrado). Programa de Pós-graduação em Educação, Universidade Federal de Juiz de Fora, Juiz de Fora, 2009. Disponível em: <http://www.ufjf.br/ppge/files/2010/04/disserta\%C3\%A7\%C3\%A3o-Julimar.pdf $>$. Acesso em: 25 jul. 2017. 
CORDEIRO, M. J. de J. A. Negros e indígenas cotistas da Universidade Estadual de Mato Grosso do Sul: desempenho acadêmico do ingresso à conclusão de curso. 2008. 260 f. Tese (Doutorado em Educação) - Pontifícia Universidade Católica de São Paulo, São Paulo, 2008. Disponível em: <https://tede2.pucsp.br/handle/handle/10055>. Acesso em: 25 jul. 2017.

CUNHA, E. M. P. Sistema universal e sistema de cotas para negros na Universidade de Brasília: um estudo de desempenho. 2006. 98 f. Dissertação (Mestrado em Educação) - Programa de Pós-Graduação em Educação, Faculdade de Educação, Universidade de Brasília, Brasília, 2006. Disponível em: <http://repositorio.unb.br/ bitstream/10482/2365/1/2006_Eglaisa\%20Micheline\%20Pontes\%20Cunha.pdf $>$.Acesso em: 25 jul. 2017.

DOEBBER, M. B. Reconhecer-se diferente é a condição de entrada - tornar-se igual é a estratégia de permanência: das práticas institucionais à constituição de estudantes cotistas negros na UFRGS. 2011. 168 f. Dissertação (Mestrado em Educação) - Universidade Federal do Rio Grande do Sul, Porto Alegre, 2011. Disponível em: $<$ http://www.lume.ufrgs. br/bitstream/handle/10183/37379/000820723.pdf? sequence=1>. Acesso em: 25 jul. 2017.

DUARTE, S. R. S. O perfil étnico-racial dos (as) ingressantes de 2009 do Instituto Federal de Educação, Ciência e Tecnologia do Pará: uma contribuição para a análise, proposição e implementação de medidas de ações afirmativas. 2011. 135 f. Dissertação (Mestrado em Educação) - Programa de Pós-Graduação em Educação, Faculdade de Educação, Universidade de Brasília, Brasília, 2011. Disponível em: <http://repositorio. unb.br/handle/10482/9121>. Acesso em: 25 jul. 2017.

EMERICH, D. R. A percepção dos professores sobre o sistema de cotas para negros da Universidade Estadual de Mato Grosso do Sul - Curso de Pedagogia de Dourados (20042008). 2011. 81 f. Dissertação (Mestrado em Educação) - Programa de Pós-Graduação em Educação, Universidade Católica Dom Bosco, Campo Grande, 2011. Disponível em: $<$ http://site.ucdb.br/public/md-dissertacoes/8190-a-percepcao-dos-professores-sobre-o-sistema-de-cotas-para-negros-da-universidade-estadual-de-mato-grosso-do-sul-curso-de-pedagogia-de-dourados-2004-2008.pdf>. Acesso em: 25 jul. 2017.

EUGÊNIO, K. M. A implementação da lei 10.639/03 por meio do Mipid em Campinas $(S P)$ : a luta pelo reconhecimento no combate ao racismo institucionalizado brasileiro. 2014. 144 f. Dissertação (Mestrado em Educação) - Programa de Pós-Graduação em Políticas Públicas e Educação, Pontifícia Universidade Católica de Campinas, Campinas, 2014. Disponível em: <http://www.bibliotecadigital.puc-campinas.edu.br/tde_busca/ arquivo.php? codArquivo=900\&PHPSESSID $=69$ bf5bed562b15f47ad6b2818ed7ce24> . Acesso em: 25 jul. 2017.

FABI, S. G. Programa Conexões de Saberes (SECAD/MEC): Implantação e implementação de uma política afirmativa no Campus do Pantanal/UFMS. 2010. 2010. 124 f. Dissertação (Mestrado em Educação) - Universidade Federal de Mato Grosso do Sul, Campo Grande, 2010. Disponível em: <http://repositorio.cbc.ufms.br:8080/jspui/ bitstream/123456789/87/1/Solange.pdf>. Acesso em: 25 jul. 2017. 
FELIPE, D. A. Negritude em discurso: a educação nas revistas Veja e Época (2003-2010). 2014. Tese (Doutorado em Educação) - Programa de Pós-Graduação em Educação, Universidade Estadual de Maringá, Maringá, 2014. Disponível em: <http://www.ppe. uem.br/teses/2014\%20-\%20Delton.pdf $>$. Acesso em: 25 jul. 2017.

FERNANDES, F. L. Políticas de ação afirmativa e acesso ao ensino superior: os impactos da introdução das leis de reserva de vagas na UERJ. 2006. 72 f. Programa de Pós-Graduação em Educação, Universidade do Estado do Rio de Janeiro, Rio de Janeiro, 2006. Disponível em: <http://www.proped.pro.br/teses/teses_pdf/2004_1-56-ME.pdf>. Acesso em: 25 jul. 2017.

FIGUEIREDO, E. S. A. de. As Ações Afirmativas na Educação Superior: política de inclusão à lógica do capital. 2008. 198 f. Dissertação (Mestrado) - Pós-Graduação em Educação, Universidade Federal Fluminense, Niterói, 2008. Disponível em: <http://www. bdtd.ndc.uff.br/tde_busca/arquivo.php?codArquivo=2983>. Acesso em: 25 jul. 2017.

GUIMARÃES, M. A. No meio do caminho tinha uma discriminação, tinha uma discriminação no meio do caminho: o potencial transformador das costas raciais. 2006. 140f. Dissertação (Mestrado em Educação) - Universidade Federal do Mato Grosso, Cuiabá, 2006. Disponível em: <htp://www.redeacaoafirmativa.ceao.ufba.br/uploads/ ufmt_dissertacao_2006_MAGuimaraes.pdf >. Acesso em: 25 jul. 2017.

JESUS, R. E. de. Ações afirmativas, educação e relações raciais: conservação, atualização ou reinvenção do Brasil? 2011. 277 f. Tese (Doutorado em Educação) - Faculdade de Educação, Universidade Federal de Minas Gerais, Belo Horizonte, 2011. Disponível em: <http://flacso.redelivre.org.br/files/2013/02/975.pdf>. Acesso em: 25 jul. 2017.

KERN, G. da S. Ações afirmativas e educação: um estudo genealógico sobre as relações raciais no Brasil. 2012. 182 f. Dissertação (Mestrado em Educação) - Faculdade de Educação, Universidade Federal do Rio Grande do Sul, Porto Alegre, 2012. Disponível em: $<$ http://www.lume.ufrgs.br/bitstream/handle/10183/56682/000860585.pdf? sequence=1>. Acesso em: 25 jul. 2017.

LOPES, T. R. Ações afirmativas: a igualdade e o acesso pleno à educação superior dos grupos sociais historicamente excluídos. 2014. 220 f. Dissertação (Mestrado em Educação) - Programa de Pós-Graduação em Educação, Universidade Federal de Santa Maria, Santa Maria, 2014. Disponível em: <http://cascavel.ufsm.br/tede/tde_busca/arquivo. php?codArquivo=6655>. Acesso em: 25 jul. 2017.

MAIA, M. G. B. Política de acesso à educação superior: o sistema de cotas para negros. 2007. 142 f. Dissertação (Mestrado em Educação) - Programa de Mestrado em Educação, Centro de Teologia e Ciências Humanas, Pontifícia Universidade Católica do Paraná, Curitiba, 2007. Disponível em: <http://flacso.redelivre.org.br/files/2013/02/988.pdf> . Acesso em: 25 jul. 2017.

MARÇAL, J. A. Política de ação afirmativa na Universidade Federal do Paraná e a formação de intelectuais negros (as). 2011. 195f. Dissertação (Mestrado em Educação) - Universidade Federal do Paraná, Curitiba, 2011. Disponível em: <http://acervodigital. 
ufpr.br/bitstream/handle/1884/25782/DISSERTACAO\%20-\%20JOSE\%20ANTONIO\%20MARCAL.pdf?sequence=1\&isAllowed=y>. Acesso em: 25 jul. 2017.

MARQUES, E. P. de S. O Programa Universidade para Todos e a inserção de negros na educação superior: a experiência de duas Instituições de Educação Superior de Mato Grosso do Sul-2005-2008. 2010. 269 f. Tese (Doutorado em Educação) - Programa de Pós-Graduação em Educação, Universidade Federal de São Carlos, São Carlos, 2010. Disponível em: <https://repositorio.ufscar.br/handle/ufscar/2244>. Acesso em: 25 jul. 2017.

MEIRA, A. P. B. Ações afirmativas na Universidade de Brasília: a opinião das estudantes oriundas do sistema de cotas. 2013. 175 f. Dissertação (Mestrado em Educação) - Programa de Pós-Graduação em Educação, Faculdade de Educação, Universidade de Brasília, Brasília, 2013. Disponível em: < http://repositorio.unb.br/bitstream/10482/13911/1/2010 AnaPaulaBarbosaMeira.pdf>. Acesso em: 25 jul. 2017.

MOEHLECKE, S. Fronteiras da igualdade no ensino superior: excelência \& justiça racial. 2004. 231 f. Tese (Doutorado em Educação) - Faculdade de Educação, Universidade de São Paulo, São Paulo, 2004. Disponível em: <http://www.teses.usp.br/teses/ disponiveis/48/48134/tde-07012005-100851/pt-br.php>. Acesso em: 25 jul. 2017.

MORAES, W. C. S. de. Ações Afirmativas e o Acesso de Negros na Educação Superior: um estudo de caso do Instituto Luther King. 2009. 158 f. Dissertação (Mestrado em Educação) - Programa de Pós-Graduação em Educação, Universidade Católica Dom Bosco, Campo Grande, 2009. Disponível em: <http://site.ucdb.br/public/md-dissertacoes/8097-acoes-afirmativas-e-o-acesso-de-negros-na-educacao-superior-um-estudo-de-caso-do-instituto-luther-king-ilk.pdf>. Acesso em: 25 jul. 2017.

NASCIMENTO, A. J. B. do. Cotas na Universidade Federal do Ceará: para quem? 2011. 148 f. Dissertação (Mestrado em Educação) - Faculdade de Educação, Universidade Federal do Ceará, Fortaleza, 2011. Disponível em: <http://www.repositorio.ufc. br/handle/riufc/3319>. Acesso em: 25 jul. 2017.

NEGRÃO, M. M. Políticas educacionais e o acesso do negro na educação superior no governo Lula. Além das cotas? 2011. Dissertação (Mestrado em Educação) - Universidade Tuiuti do Paraná, Curitiba, 2011. Disponível em: <http://tede.utp.br:8080/jspui/ handle/tede/560>. Acesso em: 25 jul. 2017.

NORÕES, K. C. Cotas raciais ou sociais? Trajetória, percalços e conquistas na implementação de ações afirmativas no ensino superior público-2001 a 2010. 2011. 300 f. Dissertação (Mestrado em Educação) - Universidade Estadual Paulista, Campinas, 2011. Disponível em < http://repositorio.unicamp.br/jspui/bitstream/REPOSIP/250971/1/ Noroes_KatiaCristina_M.pdf>.Acesso em: 25 jul. 2017.

NUNES, A. de A. C. O sistema de cotas para negros na Universidade Federal do Maranhão: uma política de ação afirmativa para a população afromaranhense. 2011. 215 f. Tese (Doutorado em Educação) - Faculdade de Filosofia e Ciência, Universidade Estadual Paulista, Marília, 2011. Disponível em: < https://repositorio.unesp.br/bitstream/ 
handle/11449/104812/nunes_aac_dr_mar.pdf?sequence $=1 \&$ isAllowed $=\mathrm{y}>$. Acesso em: 25 jul. 2017.

OLIVEIRA, A. O debate sobre cotas universitárias: itinerários da prática pedagógica na Universidade Federal de Sergipe. 211 f. Tese (Doutorado em Educação) - Programa de Pós-graduação em Educação, Universidade Federal de Sergipe, São Cristóvão, 2013. Disponível em: <http://bdtd.ufs.br/handle/tede/1633>. Acesso em: 25 jul. 2017.

OLIVEIRA, J. A. N. Estudantes negros ingressantes na universidade por meio de reserva de vagas: um estudo sobre processos educativos de construção de identidade negra e pertencimento étnico-racial no ensino superior. 2013. 122 f. Dissertação (Mestrado em Educação) - Programa de Pós-Graduação em Educação, Universidade Federal de São Carlos, São Carlos, 2013. Disponível em: <https://repositorio.ufscar.br/handle/ ufscar/2657>. Acesso em: 25 jul. 2017.

OLIVEIRA, L. F. de. As Políticas de Ação Afirmativa para negros e a possibilidade de Elaboração do Passado: Contribuições Adornianas. 2013. 125 f. Dissertação (Mestrado em Educação) - Faculdade de Ciências e Tecnologia, Universidade Estadual Paulista, Presidente Prudente, 2013. Disponível em: <https://repositorio.unesp.br/bitstream/ handle/11449/92266/oliveira_lf_me_prud.pdf?sequence=1\&isAllowed=y $>$. Acesso em: 25 jul. 2017.

PEREIRA, W. F. Prática de inclusão na universidade: representações de professores e estudantes. 2011. 275 f. Tese (Doutorado em Educação) - Faculdade de Educação, Universidade de São Paulo, 2011. Disponível em: < http://www.teses.usp.br/teses/disponiveis/48/48134/tde-01122011-152437/pt-br.php>. Acesso em: 25 jul. 2017.

PILlATTI, S. V. Política de cotas nas universidades brasileiras: possibilidade de extensão das ações afirmativas às instituições comunitárias? 2014. 152 f. Dissertação (Mestrado em Educação) - Programa de Pós-Graduação em Educação, Universidade do Oeste de Santa Catarina, Joaçaba, 2014. Disponível em: <http://www.unoesc.edu.br/ images/uploads/mestrado/Sandra_Veit_Pillatti_\%281\%29.pdf $>$. Acesso em: 25 jul. 2017.

PINHO, F. de A. As representações sociais de alunos cotistas por professores universitários: A experiência da UERJ. 2006. 117 f. Dissertação (Mestrado em Educação) Universidade Estácio de Sá, Rio de Janeiro, 2006. Disponível em: <http://www.estacio. br/mestrado/educacao/dissertacoes/Dissert_RSPE_Fabricia\%20de\%20Almeida\%20 Pinho.pdf>. Acesso em: 25 jul. 2017.

PLÁ, S. Os cotistas negros na universidade: perfis e representações. 2009. 171 f. Dissertação (Mestrado em Educação) - Pós-Graduação em Educação, Universidade Estadual de Ponta Grossa, Ponta Grossa, 2009. Disponível em: <http://www.bicen-tede.uepg.br/ tde_busca/arquivo.php?codArquivo=362>. Acesso em: 25 jul. 2017.

REIS, A. M. dos. Democratização do acesso e políticas afirmativas na educação superior. 2009. 137 f. Dissertação (Mestrado em Educação) - Programa de Pós-Graduação em Educação, Universidade de Sorocaba, Sorocaba, 2009. Disponível em: <http:// 
educacao.uniso.br/prod_cientifica/alunos/2008/Ana_Maria_dos_Reis.pdf $>$.Acesso em: 25 jul. 2017.

ROCHA, G. O. R. da et al. Reserva de vagas no ensino superior: o processo de implementação das cotas raciais nos cursos de graduação da Universidade Federal do Pará. 2011. 131 f. Dissertação (Mestrado em Educação) - Programa de Pós-Graduação em Educação, Universidade Federal do Pará, Belém, 2011. Disponível em: < http://www. redeacaoafirmativa.ceao.ufba.br/uploads/ufpa_dissertacao_2011_NBMelo.pdf $>$.Acesso em: 25 jul. 2017.

SACRAMENTO, M. P. do. Ação Afirmativa: O impacto da política de cotas na ESDI (Escola Superior De Desenho Industrial UERJ). 2005. 202 f. Dissertação (Mestrado) - Programa de Pós-Graduação em Educação, Universidade Federal Fluminense, Niterói, 2005. Disponível em: $<$ http://www.bdtd.ndc.uff.br/tde_busca/arquivo.php?codArquivo=3027>. Acesso em: 25 jul. 2017.

SALES, S. R. Justificativas, acordos e tensões: o debate sobre políticas de ação afirmativa na universidade brasileira. 2007. 166 f. Tese (Doutorado em Educação) - Programa de Pós-Graduação em Educação, Universidade do Estado do Rio de Janeiro, Rio de Janeiro, 2007. Disponível em: <http://www.proped.pro.br/teses/teses_pdf/2003_1-39-DO.pdf>. Acesso em: 25 jul. 2017.

SANTANA, E. da S. O aluno negro e o ensino superior: trajetória histórica, percalços e conquistas (análise do perfil socioeconômico e acadêmico do discente da FCT/UNESP de Presidente Prudente. 2006. 148 f. Dissertação (Mestrado em Educação) - Programa de Pós-Graduação em Educação, Universidade Estadual Paulista, Presidente Prudente, 2006. Disponível em: < http://www2.fct.unesp.br/pos/educacao/teses/eder.pdf > . Acesso em: 25 jul. 2017.

SANTANA, R. O. Efeitos da educação superior nas identidades de negros cotistas da Universidade Estadual de Mato Grosso do Sul. 2010. 125 f. Dissertação (Mestrado em Educação) - Programa de Pós-Graduação em Educação, Universidade Católica Dom Bosco, Campo Grande, 2010. Disponível em: <http://site.ucdb.br/public/md-dissertacoes/8159-efeitos-da-educacao-superior-nas-identidades-de-negros-cotistas-da-universidade-estadual-de-mato-grosso-do-sul.pdf>. Acesso em: 25 jul. 2017.

SANTOS, C. M. A mulher negra no ensino superior: Trajetórias e Desafios. 2012. 153 f. Dissertação (Mestrado) - Programa de Pós-Graduação em Educação e Contemporaneidade, Universidade do Estado da Bahia, Salvador, 2012. Disponível em: <http://www. cdi.uneb.br/pdfs/educacao/2012/1109141321.pdf>. Acesso em: 25 jul. 2017.

SANTOS, M. B. Mérito e Racismo: "tudo junto e misturado". 2011. 203 f. Tese (Doutorado) - Universidade do Estado do Rio de Janeiro, Rio de Janeiro, 2011. Disponível em <http://livrozilla.com/download/417099>. Acesso em: 25 jul. 2017.

SANTOS, M. C. E. M. Sou cotista, e agora? Uma análise das condições de permanência numa universidade multicampi. 2009. 260 f. Dissertação (Mestrado em Educação) Programa de Pós-Graduação em Educação, Universidade do Estado da Bahia, Salvador, 
2009. Disponível em: <http://www.cdi.uneb.br/pdfs/educacao/2009/maria_cristina_elyote_marques_santos.pdf $>$. Acesso em: 25 jul. 2017.

SANTOS, M. A. de O. O pertencimento racial de universitários negros da Faculdade Zumbi dos Palmares. 2012. 118 f. Dissertação (Mestrado em Educação) - Faculdade de Educação, Universidade de São Paulo, São Paulo, 2012. Disponível: http://www.teses.usp. br/teses/disponiveis/48/48134/tde-22062012-131929/pt-br.php Acesso em: 25 jul. 2017.

SANTOS, M. R. N. dos. Cotas sociorraciais: para além das classes e da raça. 2009. 157 f. Dissertação (Mestrado em Educação Brasileira) - Centro de Educação, Universidade Federal de Alagoas, 2009. Disponível em: <http://www.repositorio.ufal.br/handle/riufal $/ 345>$. Acesso em: 25 jul. 2017.

SILVA, E. A. da. Ações afirmativas na educação superior: um estudo sobre dissertações defendidas em universidades federais de 2001 a 2011. 2013. 147 f. Dissertação (Mestrado em Educação) - Programa de Pós-Graduação em Educação, Políticas Públicas e Gestão da Educação, Universidade de Brasília, Brasília, 2013. Disponível em: $<$ http:// repositorio.unb.br/bitstream/10482/12594/1/2012_EdneuzaAlvesdaSilva.pdf $>$. Acesso em: 25 jul. 2017.

SILVA, F. M. da. Programa conexões de saberes: uma política de ação afirmativa de permanência para negros moradores de favela, na universidade? 2012. Dissertação (Mestrado em Educação) - Universidade Federal Fluminense, 2012. Disponível em: $<$ https://dlc.library.columbia.edu/catalog/ldpd:504744/bytestreams/content/content?fil ename $=$ Francisco+Marcelo+da+Silva.pdf $>$. Acesso em: 25 jul. 2017.

SILVA, L. C. G. da. Políticas de Ações Afirmativas: A experiência do projeto Negraeva. 2008. 98 f. Dissertação (Mestrado em Educação) - Programa de Pós-Graduação em Educação, Universidade Católica Dom Bosco, Campo Grande, 2008. Disponível em: $<$ http://site.ucdb.br/public/md-dissertacoes/11138-politicas-de-acoes-afirmativas-a-experiencia-do-projeto-negraeva.pdf>. Acesso em: 25 jul. 2017.

SOUZA, A. C. de. Avaliação da política de cotas da UEPG: desvelando o direito à igualdade e à diferença. 2012. 248 f. Dissertação (Mestrado em Educação) - Universidade Estadual de Ponta Grossa, Ponta Grossa, 2012. Disponível em: <http://www3.uepg.br/ geppea/wp-content/uploads/sites/10/2014/06/Disserta\%C3\%A7\%C3\%A3o-Andreliza. pdf>. Acesso em: 25 jul. 2017.

SOUZA, I. M. de. Ações afirmativas na educação superior a distância: uma análise do impacto social do Sistema de Reserva de Vagas no curso de Pedagogia da UNIMONTES-UAB. 2014. 172 f. Dissertação (Mestrado em Educação) - Programa de Pós-Graduação em Educação, Faculdade de Educação, Universidade de Brasília, Brasília, 2014. Disponível em: <http://repositorio.unb.br/bitstream/10482/15201/3/2013_IvaniseMelodeSouza. pdf $>$. Acesso em: 25 jul. 2017.

SOUZA, L. O ProUni como política pública de ação afirmativa: uma análise do impacto sociocultural na trajetória de egressos, oriundos das camadas populares, do ProUni da PUC-MG. 2011. 113 f. Tese de Doutorado. Dissertação (Mestrado em Educação) - Pontifí- 
cia Universidade Católica de Minas Gerais, Belo Horizonte, 2011. Disponível em: $<$ http:// www.biblioteca.pucminas.br/teses/Educacao_SouzaLE_1.pdf>.Acesso em: 25 jul. 2017.

STROISCH, A. A permanência e o êxito dos alunos cotistas dos cursos superiores do campo São José do Instituto Federal de Santa Catarina (2009-2010). 2012. 233 f. Dissertação (Mestrado em Educação) - Universidade Estadual de Campinas, Campinas, 2012. Disponível em: <http://repositorio.unicamp.br/jspui/handle/REPOSIP/250909>. Acesso em: 25 jul. 2017.

TAVARNARO, V. G. Representações de justiça dos alunos do $5^{\circ}$ ano do curso de direito da UEPG a partir da análise do sistema de cotas raciais. 2009. 221 f. Dissertação (Mestrado em Educação) - Pós-Graduação em Educação, Universidade Estadual de Ponta Grossa, Ponta Grossa, 2009. Disponível em: $<$ http://www.bicen-tede.uepg.br/tde_busca/ arquivo.php?codArquivo=412>. Acesso em: 25 jul. 2017.

TOBIAS, J. da S. Negros e negras chegam à universidade: estudo sobre as trajetórias acadêmicas e as perspectivas profissionais dos cotistas da Unifesp. 2014. 232 f. Dissertação (Mestrado em Educação) - Faculdade de Educação, Universidade de São Paulo, São Paulo, 2014. Disponível em: <http://www.teses.usp.br/teses/disponiveis/48/48134/ tde-09122014-123631/pt-br.php>. Acesso em: 25 jul. 2017.

TOMAIN, V. R. R. Representações sociais de professores do ensino médio sobre cotas para negros na universidade. 2008. 119 f. Dissertação (Mestrado em Educação) - Programa de Pós-Graduação em Educação, Centro Universitário Moura Lacerda, Ribeirão Preto, 2008. Disponível em: $<$ http://www.dominiopublico.gov.br/pesquisa/DetalheObraForm. do?select_action=\&co_obra=126809>. Acesso em: 25 jul. 2017.

VALENTIM, D. F. D. Ex-alunos negros cotistas da UERJ: os desacreditados e o sucesso acadêmico. 2012. Tese (Doutorado em Educação) - Departamento de Educação, Pontifícia Universidade Católica do Rio de Janeiro, 2012. Disponível em: $<$ http://www2.dbd.puc-rio.br/pergamum/tesesabertas/0811292_2012_pretextual.pdf > . Acesso em: 25 jul. 2017.

VALVERDE, D. O. Para além do ensino médio: a política de cotas da Universidade de Brasília e o lugar do/a jovem negro/a na educação. 2008. 263 f. Dissertação (Mestrado em Educação) - Programa de Pós-Graduação em Educação, Faculdade de Educação, Universidade de Brasília, Brasília, 2008. Disponível em: $<$ http://repositorio.unb.br/ bitstream/10482/1722/1/2008_DanielleOliveiraValverde.pdf >. Acesso em: 25 jul. 2017.

VICENTE, J. Universidade da cidadania zumbi dos palmares: uma proposta alternativa de inclusão do negro no ensino superior. 2012. 274 f. Tese (Doutorado em Educação) -Universidade Metodista de Piracicaba, Piracicaba, 2012. Disponível em: <https:// www.unimep.br/phpg/bibdig/pdfs/docs/21062013_113237_tesejv.pdf $>$. Acesso em: 25 jul. 2017.

Texto recebido em 23 de fevereiro de 2018. Texto aprovado em 25 de fevereiro de 2018. 
